
\title{
THE UTILITARIAN SOCIAL CHOICE FUNCTIONAL
} Somdeb Lahiri ${ }^{1}$. SPM, PDPU.

\begin{abstract}
We introduce the concept of a social choice functional and provide two axiomatic characterizations of the utilitarian social choice functional. Subsequently we consider Harsanyi's weighted utilitarianism and establish two more propositions concerning the same. While the first is an axiomatic characterization of Harsanyi's weighted utilitarianism, the second provides a sufficient condition for exact Harsanyi's weighted utilitarianism.
\end{abstract}

KEYWORDS: social choice functional, evaluation function, utilitarian, weighted utilitarian

MSC: 91B14, 90B50, 91B06

JEL: D71.

\section{RESUMEN}

Introducimos el concepto de una opción social funcional y proporcionamos dos caracterizaciones axiomáticas de la opción social utilitaria funcional. Posteriormente, consideramos el utilitarismo ponderado de Harsanyi y establecemos dos proposiciones más sobre el mismo. Mientras que el primero es una caracterización axiomática del utilitarismo ponderado de Harsanyi, el segundo proporciona una condición suficiente para el utilitarismo ponderado de Harsanyi exacto.

PALABRAS CLAVE: opción social funcional, función de evaluación, utilitaria, utilitaria ponderada.

\section{INTRODUCTION}

A social choice correspondence (as defined for instance in Denicolo (1985)) is a function which assigns to each profile of individual preferences (rankings with ties) over a set of outcomes or alternatives, a non-empty set of alternatives. A social choice correspondence is a set-valued generalization of a social choice function due to Gibbard (1973) and Satterthwaite (1975). Each ranking could represent the preferences of a voter over the set of alternatives (or candidates) or the ranking along a criterion by an individual decision maker or the ranking of the alternatives for a particular state of nature. Most results for social choice correspondences are in the Arrovian tradition, exhibiting incompatibility of a small set of desirable properties. Significant exceptions to these so called "impossibility theorems" are possibility results by Alemante, Campbell and Kelly (2016), Kelly and Qi (2018) are Kelly (2018) to mention a few. The framework of social choice correspondences is another way of representing and investigating the preference aggregation problem that began with the work of Arrow. In Sen (1970), there is a representation of the aggregation problem due to Arrow, where individual preferences, whether they be of several decision makers or they represent preference along criteria of a single decision maker, are represented by numerical (real-valued) evaluation functions rather than rankings. Sen's purpose was to incorporate interpersonal comparisons of utility in social choice theory. In multi-criteria decision making, measurement along a criteria by an evaluation function, rather than a ranking of alternatives, is absolutely necessary for the theory to be meaningful. This has been pointed out in Lahiri (2018) with the help of the following example. "For instance when it comes to evaluating PCs, the trade-offs between more memory and a higher price may depend not only on the fact that one has to pay a higher price for an expanded memory size but also upon the magnitude of the increments. This cannot be effectively captured unless we have numerical representation of our preferences along each criterion which expresses the intensity of preference along that criterion." Rubinstein (2012) discusses the interpretation of preference aggregation problems as aggregation of rankings along several criteria, but fails to point out the incompleteness of such an analysis unless preferences along a criterion are represented by evaluation functions rather than rankings. Sen | (1970), refers to the rule by which profiles of evaluation functions are aggregated into a ranking of

\footnotetext{
${ }^{1}$ somdeb.lahiri@gmail.com
} 
alternatives, as a social welfare functional. A contemporary survey of results relating to social welfare functionals can be found in d'Aspremont and Gevers (2002).

In this paper, we formally introduce the concept of a social choice functional, which is a rule which assigns to each evaluation profile, a non-empty subset of alternatives. An evaluation profile assigns to each voter/criterion/state of nature, an evaluation function. The alternatives from which possible choices are to be made could be candidates in an election (as in the context of voting) or any other collection of options from which a single individual or group of individuals have to make a choice. In case it is a problem faced by a single decision maker, then we are in the realm of multi-criteria decision theory or choice under complete uncertainty.

We then define the utilitarian social choice functional and provide two axiomatic characterizations for it. The utilitarian social choice functional chooses at each evaluation profile, exactly those alternatives which maximize the sum of the evaluations. For both axiomatic characterizations, we require the familiar weak Pareto criterion and Pareto indifference. Further for both axiomatic characterizations we invoke the independence of irrelevant alternatives property (which has a familiar analogous definition for social choice correspondences available in Denicolo (1993)). The combination of Pareto indifference and independence of irrelevant alternatives is equivalent to a property called strong neutrality. We prove this very useful result. For corresponding definitions and results in the context of social welfare functionals one may refer to d'Aspremont and Gevers (2002). A comparison will show that while our terminology may be same in some cases be similar to those used for social welfare functional, the difference in the two frameworks do not permit an easy translation of definitions and proofs from one context to the other. For the first axiomatic characterization, we use in addition a property which we refer to as insensitivity to binary transfers. For the second axiomatic characterization, we use a property that we refer to as treating binary invariants almost equally. It is easy to see that a social choice functional that treats binary invariants equally also satisfies Pareto indifference. Earlier work in this direction that we are aware of is the paper by Hillinger (2005). Our methodology is original. We do not use axioms pertaining to the invariance of choice sets under transformations of the evaluation profiles; nor do we use social welfare orderings to obtain our axiomatic characterizations.

Subsequently we consider Harsanyi's weighted utilitarianism which is a property that selects alternatives from those which maximize a weighted sum of the individual evaluations. As in Harsanyi's pioneering work on the subject (Harsanyi (1955)), the weights attached to the individual evaluations, may depend on the evaluation profile under consideration. This is precisely where our similarity with the Harsanyi (1955) model ends. It is worth mentioning that Harsanyi's legacy has been carried forward in the much-acclaimed papers of Dhillon (1998) and Dhillon and Mertens (1999). Unlike Harsanyi, we assume that the weights of the evaluation functions are non-negative and add up to one. Thus, if the individuals are states of nature as in choice under complete uncertainty, then the weights could be interpreted as a profile dependent probability distribution over the states of nature. In particular negative weights are not allowed. This is not a major restriction, since in the case of a negative weight, we could consider the negative of the evaluation function, instead of the one we are given and to which the weights are assigned. The major respect in which we break free of the Harsanyi tradition is that we consider a finite set of alternatives from which choices have to be made, whereas Harsanyi's set of alternatives are lotteries over a finite set of alternatives, i.e. a finite dimensional simplex. Along with lotteries over a finite set of alternatives, comes the paraphernalia of von-Neumann Morgenstern utility functions, all of which are very distant from the concerns of our paper. In fact, there is considerable divergence of opinion on how much of Harsanyi's framework is really intrinsic to weighted utility maximization. We prefer to stay away from that debate in this paper and stick to axiomatic analysis for the present. We use Farkas' lemma to prove our results concerning Harsanyi's weighted utilitarianism. Our first result in this context says that a social choice functional satisfies Harsanyi's weighted utilitarianism if and only if there does exist any probability distribution on alternatives along with a probability distribution on the set of chosen alternatives such that for every individual/criterion/state of nature, the expected utility of an alternative belonging to the universal set of alternatives is greater than the expected utility of an alternative being a chosen alternative. We call this criterion the non-existence property. To the best of our knowledge (including those the author consulted while preparing this paper), there is no such precedent in the social choice theory literature. However, there is a kind of similarity between this result and the arbitrage theorem of mathematical finance, as stated and proved for instance in theorem 4.4.1 of Ross (2000). Earlier applications of Farkas' lemma to problems considerably different from the one we consider can be found in Scott (1964). For readers, enthusiastic about expected utility maximization a good source of applicable results in the case of 
a finite set of alternatives, is the paper by Shapiro (1977). Our result does not appear there; nor does it seem to follow as an immediate corollary of some result in the papers that we have cited in this paper.

A slightly stronger criterion than Harsanyi's weighted utilitarianism is that at each evaluation profile the chosen set should coincide with (and not merely be a subset of) the set of weighted utility maximizers for some non-negative weights which add to one. We call this criterion exact Harsanyi's weighted utilitarianism. A sufficient condition for exact Harsanyi's weighted utilitarianism is the strong non-existence property. The strong non-existence property requires that in addition to the non-existence property the following additional property be satisfied: for each un-chosen alternative, there exists a probability distribution on the universal set of alternatives and a probability distribution on the set of chosen alternative including the un-chosen one, such that every individual the expected utility of the alternative belonging to the universal set is greater than the expected utility of the smaller set. In simpler terms, this additional property requires that if the chosen set of alternatives is expanded by including an un-chosen alternative, then the non-existence property breaks down.

\section{THE FRAMEWORK}

Let $\mathrm{X}$ be a non-empty finite set of alternatives/candidates containing at least three elements and let $\Psi(\mathrm{X})$ denote the set of all non-empty subsets of $X$. Any element of $\Psi(X)$ is referred to as an agenda/menu. For a positive integer $n \geq 3$, let $N=\{1,2, \ldots, n\}$ denote the set of criteria/states of nature/voters.

An evaluation function is a function $u: X \rightarrow \mathbb{R}$ which gives for each alternative its worth/pay-off/evaluation. Each voter/criteria/state of nature has an evaluation function. Let $\mathcal{U}$ denote the set of all evaluation functions. An evaluation profile is an $n$-tuple of evaluation functions $U=\left(u_{1}, u_{2}, \ldots, u_{n}\right)$, where $u_{i}$ denotes the evaluation function of voter $\mathrm{i} /$ along criteria $\mathrm{i} /$ at state of nature $\mathrm{i}$. The set of all evaluation profiles is $\mathcal{U}^{\mathrm{n}}$.

An admissible set (of evaluation profiles) is a non-empty subset $\mathcal{D}$ of $\mathcal{U}^{\mathrm{n}}$.

A social choice functional (SCFL) on an admissible set $\mathcal{D}$ is a function $\mathrm{F}: \mathcal{D} \rightarrow \Psi(\mathrm{X})$.

An SCFL $F$ on $\mathcal{D}$ is said to be the utilitarian SCFL if for all $U=\left(u_{1}, u_{2}, \ldots, u_{n}\right) \in \mathcal{D}, F(U)=$ $\operatorname{Argmax}_{\mathrm{x} \in \mathrm{x}} \sum_{\mathrm{i}=1}^{\mathrm{n}} \mathrm{u}_{\mathrm{i}}(\mathrm{x})$.

Let $\mathcal{U}_{+}=\{\mathrm{u} \in \mathcal{U} \mid \mathrm{u}(\mathrm{x}) \geq 0$ for all $\mathrm{x} \in \mathrm{X}\}$ and $\mathcal{U}_{++}=\{\mathrm{u} \in \mathcal{U} \mid \mathrm{u}(\mathrm{x})>0$ for all $\mathrm{x} \in \mathrm{X}\}$. Two interesting admissible sets are $\mathcal{U}_{+}^{\mathrm{n}}$ and $\mathcal{U}_{++}^{\mathrm{n}}$.

An SCFL F on $\mathcal{D}$ where $\mathcal{D}$ is a subset of $\mathcal{U}_{+}^{\mathrm{n}}$ and $\mathcal{U}_{++}^{\mathrm{n}}$ is said to be the Nash SCFL if for all $\mathrm{U}=$ $\left(\mathrm{u}_{1}, \mathrm{u}_{2}, \ldots, \mathrm{u}_{\mathrm{n}}\right) \in \mathcal{D}, \mathrm{F}(\mathrm{U})=\operatorname{Argmax}_{\mathrm{x} \in \mathrm{X}} \prod_{\mathrm{i}=1}^{\mathrm{n}} \mathrm{u}_{\mathrm{i}}(\mathrm{x})$.

In this paper, we shall be concerned with the utilitarian SCFL and will not dwell on the Nash SCFL any further.

An SCFL F on $\mathcal{D}$ is said to satisfy the Weak Pareto criterion if for all $U=\left(\mathrm{u}_{1}, \mathrm{u}_{2}, \ldots, \mathrm{u}_{\mathrm{n}}\right) \in \mathcal{D}$ and $\mathrm{x}, \mathrm{y} \in \mathrm{X}, \mathrm{u}_{\mathrm{i}}(\mathrm{x})$ $>\mathrm{u}_{\mathrm{i}}(\mathrm{y})$ for all $\mathrm{i} \in \mathrm{N}$ implies $\mathrm{y} \notin \mathrm{F}(\mathrm{U})$.

An SCFL F on $\mathcal{D}$ is said to satisfy Pareto Indifference (PI) if for all $U=\left(\mathrm{u}_{1}, \mathrm{u}_{2}, \ldots, \mathrm{u}_{\mathrm{n}}\right)$ and $\mathrm{x}, \mathrm{y} \in \mathrm{X}$ with $\mathrm{x} \neq \mathrm{y}$, the following holds: $\left[u_{i}(x)=u_{i}(y)\right.$ for all $i \in N$ and $\left.x \in F(U)\right]$ implies $[y \in F(U)]$.

An SCFL $F$ on $\mathcal{D}$ is said to satisfy Independence of Irrelevant Alternatives (WIIA) if for all $U=$

$\left(\mathrm{u}_{1}, \mathrm{u}_{2}, \ldots, \mathrm{u}_{\mathrm{n}}\right), \mathrm{V}=\left(\mathrm{v}_{1}, \mathrm{v}_{2}, \ldots, \mathrm{v}_{\mathrm{n}}\right) \in \mathcal{D}$ and $\mathrm{x}, \mathrm{y} \in \mathrm{X}$ with $\mathrm{x} \neq \mathrm{y}$, the following holds: $\left[\mathrm{u}_{\mathrm{i}}(\mathrm{x})=\mathrm{v}_{\mathrm{i}}(\mathrm{x}), \mathrm{u}_{\mathrm{i}}(\mathrm{y})=\mathrm{v}_{\mathrm{i}}(\mathrm{y})\right.$ for all $i \in N, x \in F(U)]$ implies $[y \notin F(V)]$.

Given evaluation profiles $U=\left(\mathrm{u}_{1}, \mathrm{u}_{2}, \ldots, \mathrm{u}_{\mathrm{n}}\right), \mathrm{V}=\left(\mathrm{v}_{1}, \mathrm{v}_{2}, \ldots, \mathrm{v}_{\mathrm{n}}\right)$ and $\mathrm{x} \in \mathrm{X}, \mathrm{V}$ is said to be obtained via a binary transfer from $U$ at $x$ if there exists $i, j$ such that:

(i) $\mathrm{v}_{\mathrm{k}}(\mathrm{y})=\mathrm{u}_{\mathrm{k}}(\mathrm{y})$ for all $\mathrm{k} \in \mathrm{N}, \mathrm{y} \in \mathrm{X} \backslash\{\mathrm{x}\}$;

(ii) $\mathrm{v}_{\mathrm{k}}(\mathrm{x})=\mathrm{u}_{\mathrm{k}}(\mathrm{x})$ for all $\mathrm{k} \in \mathrm{N} \backslash\{\mathrm{i}, \mathrm{j}\}$;

(iii) $\sum_{\mathrm{k}=1}^{\mathrm{n}} \mathrm{v}_{\mathrm{k}}(\mathrm{x})=\sum_{\mathrm{k}=1}^{\mathrm{n}} \mathrm{u}_{\mathrm{k}}(\mathrm{x})$.

An SCFL F on $\mathcal{D}$ is said to be insensitive to binary transfers if for all $U=\left(\mathrm{u}_{1}, \mathrm{u}_{2}, \ldots, \mathrm{u}_{\mathrm{n}}\right), \mathrm{V}=\left(\mathrm{v}_{1}, \mathrm{v}_{2}, \ldots, \mathrm{v}_{\mathrm{n}}\right) \in \mathcal{D}$ and $\mathrm{x} \in \mathrm{X}, \mathrm{V}$ is obtained via a binary transfer from $\mathrm{U}$ at $\mathrm{x}$ and $\mathrm{x} \notin \mathrm{F}(\mathrm{U})$ implies there exists $\mathrm{U}^{1}=\left(\mathrm{u}_{1}^{1}, \ldots, \mathrm{u}_{\mathrm{n}}^{1}\right) \in \mathcal{D}$ and $y, z, w$ (possibly depending on $x, U$ and $V$ ) with $y \in F(U), z \in F\left(U^{1}\right), w \notin F\left(U^{1}\right)$, satisfying $u_{k}^{1}(z)=u_{k}(y)$ and $\mathrm{u}_{\mathrm{k}}^{1}(\mathrm{w})=\mathrm{v}_{\mathrm{k}}(\mathrm{x})$ for all $\mathrm{k} \in \mathrm{N}$.

Given an evaluation profile $\mathrm{U}=\left(\mathrm{u}_{1}, \mathrm{u}_{2}, \ldots, \mathrm{u}_{\mathrm{n}}\right)$ and $\mathrm{x}, \mathrm{y} \in \mathrm{X}$, $\mathrm{y}$ is said to be a binary variant of $\mathrm{x}$ if there exists $\mathrm{i}, \mathrm{j}$ such that:

(i) $\mathrm{u}_{\mathrm{k}}(\mathrm{x})=\mathrm{u}_{\mathrm{k}}(\mathrm{y})$ for all $\mathrm{k} \in \mathrm{N} \backslash\{\mathrm{i}, \mathrm{j}\}$;

(ii) $\sum_{\mathrm{k}=1}^{\mathrm{n}} \mathrm{u}_{\mathrm{k}}(\mathrm{x})=\sum_{\mathrm{k}=1}^{\mathrm{n}} \mathrm{u}_{\mathrm{k}}(\mathrm{y})$. 
An SCFL $F$ on $\mathcal{D}$ is said to treat binary variants almost equally if for all $U=\left(\mathrm{u}_{1}, \mathrm{u}_{2}, \ldots, \mathrm{u}_{\mathrm{n}}\right) \in \mathcal{D}$ and $\mathrm{x}, \mathrm{y} \in \mathrm{X}$, if $\mathrm{y}$ is a binary variant of $\mathrm{x}$ and $\mathrm{x} \notin \mathrm{F}(\mathrm{U})$ then there exists a $\mathrm{V}=\left(\mathrm{v}_{1}, \mathrm{v}_{2}, \ldots, \mathrm{v}_{\mathrm{n}}\right) \in \mathcal{D}$ and $\mathrm{a}, \mathrm{w}, \mathrm{z} \in \mathrm{X}$ (possibly depending on $U$, $x$ and $y)$ such that $w \in F(U), z \in F(V), a \notin F(V), v_{k}(z)=u_{k}(w)$ and $v_{k}(a)=u_{k}(y)$ for all $k \in N$.

\section{SOME IMPORTANT LEMMAS}

We begin with a crucial definition.

An SCFL F on $\mathcal{D}$ is said to satisfy Strong Neutrality (SN) if for all $U=\left(\mathrm{u}_{1}, \ldots, \mathrm{u}_{\mathrm{n}}\right), \mathrm{V}=\left(\mathrm{v}_{1}, \ldots, \mathrm{v}_{\mathrm{n}}\right) \in \mathcal{D}$ and $\mathrm{x}, \mathrm{y}, \mathrm{z}, \mathrm{w} \in \mathrm{X}:\left[\mathrm{u}_{\mathrm{i}}(\mathrm{x})=\mathrm{v}_{\mathrm{i}}(\mathrm{z}), \mathrm{u}_{\mathrm{i}}(\mathrm{y})=\mathrm{v}_{\mathrm{i}}(\mathrm{w})\right.$ for all $\mathrm{i} \in \mathrm{N}, \mathrm{x} \in \mathrm{F}(\mathrm{U})$ and $\left.\mathrm{y} \notin \mathrm{F}(\mathrm{U})\right]$ implies $[\mathrm{w} \notin \mathrm{F}(\mathrm{V})]$.

Lemma 1: An SCFL F on $\mathcal{U}^{\mathrm{n}}$ satisfies $\mathrm{SN}$ if and only if it satisfies PI and IIA.

Proof: Suppose F on $\mathcal{U}^{\mathrm{n}}$ satisfies SN.

Let $\mathrm{U}=\left(\mathrm{u}_{1}, \ldots, \mathrm{u}_{\mathrm{n}}\right) \in \mathcal{U}^{\mathrm{n}}$ and $\mathrm{x}, \mathrm{y} \in \mathrm{X}$ with $\mathrm{u}_{\mathrm{i}}(\mathrm{x})=\mathrm{u}_{\mathrm{i}}(\mathrm{y})$ for all $\mathrm{i} \in \mathrm{N}$. Let $\mathrm{x} \in \mathrm{F}(\mathrm{U})$. To show $\mathrm{y} \in \mathrm{F}(\mathrm{U})$. Towards a contradiction suppose $\mathrm{y} \notin \mathrm{F}(\mathrm{U})$.

Let $\mathrm{V}=\left(\mathrm{v}_{1}, \ldots, \mathrm{v}_{\mathrm{n}}\right) \in \mathcal{U}^{\mathrm{n}}$ with $\mathrm{v}_{\mathrm{i}}(\mathrm{a})=\mathrm{u}_{\mathrm{i}}(\mathrm{x})$ for all $\mathrm{a} \in \mathrm{X}$ and $\mathrm{i} \in \mathrm{N}$.

Let $\mathrm{z}=\mathrm{x}$ and $\mathrm{w} \neq \mathrm{x}$. Then, $\mathrm{v}_{\mathrm{i}}(\mathrm{z})=\mathrm{u}_{\mathrm{i}}(\mathrm{x})$ for all $\mathrm{i} \in \mathrm{N}, \mathrm{v}_{\mathrm{i}}(\mathrm{w})=\mathrm{u}_{\mathrm{i}}(\mathrm{y})$ for all $\mathrm{i} \in \mathrm{N}, \mathrm{x} \in \mathrm{F}(\mathrm{U}), \mathrm{y} \notin \mathrm{F}(\mathrm{U})$ and $\mathrm{SN}$ implies $\mathrm{w} \notin \mathrm{F}(\mathrm{V})$.

Thus, $\mathrm{F}(\mathrm{V}) \subset\{\mathrm{x}\}$.

Let $\mathrm{w}=\mathrm{x}$ and $\mathrm{z} \neq \mathrm{x}$. Then, $\mathrm{v}_{\mathrm{i}}(\mathrm{z})=\mathrm{u}_{\mathrm{i}}(\mathrm{x})$ for all $\mathrm{i} \in \mathrm{N}, \mathrm{v}_{\mathrm{i}}(\mathrm{w})=\mathrm{u}_{\mathrm{i}}(\mathrm{y})$ for all $\mathrm{i} \in \mathrm{N}, \mathrm{x} \in \mathrm{F}(\mathrm{U}), \mathrm{y} \notin \mathrm{F}(\mathrm{U})$ and $\mathrm{SN}$ implies $\mathrm{w} \notin \mathrm{F}(\mathrm{V})$. Thus $\mathrm{x} \notin \mathrm{F}(\mathrm{V})$.

Hence $\mathrm{F}(\mathrm{V})=\phi$, leading to a contradiction.

Thus, $\mathrm{y} \in \mathrm{F}(\mathrm{U})$.

Interchanging the roles of $x$ and $y$ in the above argument we get that if $y \in F(U)$ then $x \in F(U)$.

Thus, F satisfies PI.

Now let $\mathrm{U}=\left(\mathrm{u}_{1}, \ldots, \mathrm{u}_{\mathrm{n}}\right), \mathrm{V}=\left(\mathrm{v}_{1}, \ldots, \mathrm{v}_{\mathrm{n}}\right) \in \mathcal{U}^{\mathrm{n}}, \mathrm{x}, \mathrm{y} \in \mathrm{X}$ with $\mathrm{v}_{\mathrm{i}}(\mathrm{x})=\mathrm{u}_{\mathrm{i}}(\mathrm{x})$ and $\mathrm{v}_{\mathrm{i}}(\mathrm{y})=\mathrm{u}_{\mathrm{i}}(\mathrm{y})$ for all $\mathrm{i} \in \mathrm{N}$. Suppose $\mathrm{x} \in \mathrm{F}(\mathrm{U})$ and $\mathrm{y} \notin \mathrm{F}(\mathrm{U})$.

By taking $\mathrm{z}=\mathrm{x}, \mathrm{w}=\mathrm{y}$ and applying the definition of $\mathrm{SN}$, we get $\mathrm{y} \notin \mathrm{F}(\mathrm{V})$.

Thus, F satisfies IIA.

Now suppose F satisfies PI and IIA.

Let $\mathrm{U}=\left(\mathrm{u}_{1}, \ldots, \mathrm{u}_{\mathrm{n}}\right), \mathrm{V}=\left(\mathrm{v}_{1}, \ldots, \mathrm{v}_{\mathrm{n}}\right) \in \mathcal{U}^{\mathrm{n}}$ and $\mathrm{x}, \mathrm{y}, \mathrm{z}, \mathrm{w} \in \mathrm{X}$ with $\mathrm{u}_{\mathrm{i}}(\mathrm{x})=\mathrm{v}_{\mathrm{i}}(\mathrm{z}), \mathrm{u}_{\mathrm{i}}(\mathrm{y})=\mathrm{v}_{\mathrm{i}}(\mathrm{w})$ for all $\mathrm{i} \in \mathrm{N}$. Suppose $\mathrm{x} \in \mathrm{F}(\mathrm{U})$ and $\mathrm{y} \notin \mathrm{F}(\mathrm{U})$. By PI, $\mathrm{u}_{\mathrm{i}}(\mathrm{x}) \neq \mathrm{u}_{\mathrm{i}}(\mathrm{y})$ for some $\mathrm{i} \in \mathrm{N}$, so that $\mathrm{x} \neq \mathrm{y}$ and $\mathrm{z} \neq \mathrm{w}$. We want to show that $\mathrm{w} \notin \mathrm{F}(\mathrm{V})$.

Let $U^{1}=\left(u_{1}^{1}, \ldots, u_{n}^{1}\right) \in \mathcal{U}^{n}$, satisfy $u_{i}^{1}(x)=u_{i}^{1}(z)$ for all $i \in N, u_{i}^{1}(a)=u_{i}(y)$ for all $i \in N$ and $a \notin\{x, z\}$.

By IIA, $y \notin F\left(U^{1}\right)$ and by PI, $a \notin F\left(U^{1}\right)$ if $a \notin\{x, z\}$.

Thus, $\mathrm{F}\left(\mathrm{U}^{1}\right) \subset\{\mathrm{x}, \mathrm{z}\}$.

By PI, either both $x, z$ belong to $F\left(U^{1}\right)$ or neither do.

Since $F\left(U^{1}\right) \neq \phi$, it must be the case that $F\left(U^{1}\right)=\{x, z\}$.

Thus, $\mathrm{z} \in \mathrm{F}\left(\mathrm{U}^{1}\right)$ and $\mathrm{w} \notin \mathrm{F}\left(\mathrm{U}^{1}\right)$.

Since $\mathrm{u}_{\mathrm{i}}^{1}(\mathrm{z})=\mathrm{v}_{\mathrm{i}}(\mathrm{z}), \mathrm{u}_{\mathrm{i}}^{1}(\mathrm{w})=\mathrm{v}_{\mathrm{i}}(\mathrm{w})$ for all $\mathrm{i} \in \mathrm{N}, \mathrm{z} \in \mathrm{F}\left(\mathrm{U}^{1}\right)$ and $\mathrm{w} \notin \mathrm{F}\left(\mathrm{U}^{1}\right)$, by IIA we get $\mathrm{w} \notin F(V)$.

Thus, F satisfies SN.

This proves the lemma. Q.E.D.

An SCFL F on $\mathcal{D}$ is said to be strongly insensitive to binary transfers if for all $U=\left(\mathrm{u}_{1}, \mathrm{u}_{2}, \ldots, \mathrm{u}_{\mathrm{n}}\right), \mathrm{V}=$ $\left(\mathrm{v}_{1}, \mathrm{v}_{2}, \ldots, \mathrm{v}_{\mathrm{n}}\right) \in \mathcal{D}$ and $\mathrm{x} \in \mathrm{X}, \mathrm{V}$ is obtained via a binary transfer from $\mathrm{U}$ at $\mathrm{x}$ and $\mathrm{x} \notin \mathrm{F}(\mathrm{U})$ implies $\mathrm{x} \notin \mathrm{F}(\mathrm{V})$.

Lemma 2: Let $\mathrm{F}$ be an SCFL on $\mathcal{U}^{\mathrm{n}}$ satisfying PI and IIA. If F is insensitive to binary transfers, then it is strongly insensitive to binary transfers.

Proof: By lemma 1, F satisfies SN. Let $\mathrm{U}=\left(\mathrm{u}_{1}, \mathrm{u}_{2}, \ldots, \mathrm{u}_{\mathrm{n}}\right), \mathrm{V}=\left(\mathrm{v}_{1}, \mathrm{v}_{2}, \ldots, \mathrm{v}_{\mathrm{n}}\right) \in \mathcal{U}^{\mathrm{n}}$ and $\mathrm{x} \in \mathrm{X}$, where $\mathrm{V}$ is obtained via a binary transfer from $U$ at $x$. Suppose $x \notin F(U)$. Since $F$ is insensitive to binary transfers, there exists $\mathrm{U}^{1}=\left(\mathrm{u}_{1}^{1}, \ldots, \mathrm{u}_{\mathrm{n}}^{1}\right) \in \mathcal{D}$ and $\mathrm{y}, \mathrm{z}, \mathrm{w}$ (possibly depending on $\mathrm{x}, \mathrm{U}$ and $\mathrm{V}$ ) with $\mathrm{y} \in \mathrm{F}(\mathrm{U}), \mathrm{z} \in \mathrm{F}\left(\mathrm{U}^{1}\right), \mathrm{w} \notin \mathrm{F}\left(\mathrm{U}^{1}\right)$, satisfying $u_{k}^{1}(z)=u_{k}(y)$ and $u_{k}^{1}(w)=v_{k}(x)$ for all $k \in N$. Now, $u_{k}^{1}(z)=u_{k}(y)=v_{k}(y)$ for all $k \in N$. Thus by $S N$, $\mathrm{x} \notin \mathrm{F}(\mathrm{V})$.

Thus, $\mathrm{F}$ is strongly insensitive to binary transfers. Q.E.D.

An SCFL $F$ on $\mathcal{D}$ is said to treat binary variants equally if for all $U=\left(\mathrm{u}_{1}, \mathrm{u}_{2}, \ldots, \mathrm{u}_{\mathrm{n}}\right) \in \mathcal{D}$ and $\mathrm{x}, \mathrm{y} \in \mathrm{X}$, if $\mathrm{y}$ is a binary variant of $\mathrm{x}$ and $\mathrm{x} \notin \mathrm{F}(\mathrm{U})$ then it is the case that $\mathrm{y} \notin \mathrm{F}(\mathrm{U})$. 
Note: It is easy to see that if an SCFL F on $\mathcal{D}$ treats binary variants equally, then it satisfies Pareto Indifference.

Lemma 3: Let $\mathrm{F}$ be an SCFL on $\mathcal{U}^{\mathrm{n}}$ satisfying PI and IIA. If $\mathrm{F}$ treats binary variants almost equally then it treats binary variants equally.

Proof: By lemma 1, F satisfies SN. The rest of the proof follows almost immediately from the choice of V,a,z,w. Q.E.D.

\section{TWO PROPOSITIONS ON UTILITARIANISM}

In this section, we provide two axiomatic characterizations of the utilitarian social choice functional.

Proposition 1: The only social choice functional on $\mathcal{U}^{\mathrm{n}}$ that satisfies the Weak Pareto criterion, Pareto Indifference criterion, IIA and is insensitive to binary transfers is the utilitarian SCFL.

Proof: It is easy to see that the utilitarian SCFL satisfies the Weak Pareto criterion, Pareto Indifference, IIA and is insensitive to binary transfers. Hence let F be an SCFL on $\mathcal{U}^{\mathrm{n}}$ that satisfies the Weak Pareto criterion, Pareto Indifference, IIA and is insensitive to binary transfers. By lemma 2, F is strongly insensitive to binary transfers. We need to show that for all $U=\left(\mathrm{u}_{1}, \mathrm{u}_{2}, \ldots, \mathrm{u}_{\mathrm{n}}\right), \mathrm{F}(\mathrm{U}) \subset \operatorname{Argmax}_{\mathrm{w} \in \mathrm{X}} \sum_{\mathrm{i}=1}^{\mathrm{n}} \mathrm{u}_{\mathrm{i}}(\mathrm{w})$..

Let $\mathrm{U}=\left(\mathrm{u}_{1}, \mathrm{u}_{2}, \ldots, \mathrm{u}_{\mathrm{n}}\right)$ be an evaluation profile and let $\mathrm{x}, \mathrm{y} \in \mathrm{X}$ with $\sum_{\mathrm{i}=1}^{\mathrm{n}} \mathrm{u}_{\mathrm{i}}(\mathrm{x})>\sum_{\mathrm{i}=1}^{\mathrm{n}} \mathrm{u}_{\mathrm{i}}(\mathrm{y})$. Let us show that $\mathrm{y} \notin \mathrm{F}(\mathrm{U})$.

If $\mathrm{u}_{\mathrm{i}}(\mathrm{x})>\mathrm{u}_{\mathrm{i}}(\mathrm{y})$ for all $\mathrm{i} \in \mathrm{N}$, then by the Weak Pareto criterion $\mathrm{y} \notin \mathrm{F}(\mathrm{U})$ and we are done. Hence suppose that it is not the case that $\left[u_{i}(x)>u_{i}(y)\right.$ for all $\left.i \in N\right]$.

Let $\alpha=\left(\alpha_{1}, \ldots, \alpha_{n}\right)$ be a point in $\mathbb{R}^{n}$ such that $\mathrm{u}_{\mathrm{i}}(\mathrm{x})>\alpha_{\mathrm{i}}$ for all $\mathrm{i} \in \mathrm{N}$ and $\sum_{\mathrm{i}=1}^{\mathrm{n}} \alpha_{\mathrm{i}}=\sum_{\mathrm{i}=1}^{\mathrm{n}} \mathrm{u}_{\mathrm{i}}(\mathrm{y})$. For instance $\alpha_{\mathrm{i}}=$ $\mathrm{u}_{\mathrm{i}}(\mathrm{x})-\frac{\sum_{\mathrm{i}=1}^{\mathrm{n}} \mathrm{u}_{\mathrm{i}}(\mathrm{x})-\sum_{\mathrm{i}=1}^{\mathrm{n}} \mathrm{u}_{\mathrm{i}}(\mathrm{y})}{\mathrm{n}}$ for all $\mathrm{i} \in \mathrm{N}$, would serve our purpose. Clearly $\alpha \neq\left(\mathrm{u}_{1}(\mathrm{y}), \ldots, \mathrm{u}_{\mathrm{n}}(\mathrm{y})\right)$.

Consider the evaluation profile $\mathrm{V}^{(1)}=\left(\mathrm{v}_{1}^{1}, \mathrm{v}_{2}^{1}, \ldots, \mathrm{v}_{\mathrm{n}}^{1}\right)$ where:

(i) $v_{i}^{1}(x)=u_{i}(x)$ for all $i \in N$;

(ii) $v_{i}^{1}(y)=\alpha_{i}$ for all $i \in N$;

(iii) $\mathrm{v}_{\mathrm{i}}^{1}(\mathrm{w})<\mathrm{u}_{\mathrm{i}}(\mathrm{x})$ for all $\mathrm{i} \in \mathrm{N}$ and $\mathrm{w} \in \mathrm{X} \backslash\{\mathrm{x}, \mathrm{y}\}$.

By Weak Pareto- criterion $F\left(V^{(1)}\right)=\{x\}$.

Let $\mathrm{A}_{1}=\left\{\mathrm{i} \mid \alpha_{\mathrm{i}}>\mathrm{u}_{\mathrm{i}}(\mathrm{y})\right\}$ and $\mathrm{B}_{1}=\left\{\mathrm{i} \mid \alpha_{\mathrm{i}}<\mathrm{u}_{\mathrm{i}}(\mathrm{y})\right\}$. Clearly, $\mathrm{A}_{1}, \mathrm{~B}_{1} \neq \phi$. Without loss of generality suppose $1 \in \mathrm{A}_{1}$, $2 \in \mathrm{B}_{1}$.

Case 1: $\alpha_{1}-\mathrm{u}_{1}(\mathrm{y}) \leq \mathrm{u}_{2}(\mathrm{y})-\alpha_{2}$.

Consider the vector $\alpha^{(1)}=\left(u_{1}(y), \alpha_{2}+\left(\alpha_{1}-u_{1}(y)\right), \alpha_{3}, \ldots, \alpha_{n}\right)$.

Let $\mathrm{V}^{(2)}=\left(\mathrm{v}_{1}^{2}, \mathrm{v}_{2}^{2}, \ldots, \mathrm{v}_{\mathrm{n}}^{2}\right)$ be the evaluation profile such that:

(i) $v_{\mathrm{i}}^{2}(\mathrm{w})=\mathrm{v}_{\mathrm{i}}^{1}(\mathrm{w})$ for all $\mathrm{i} \in \mathrm{N}$ and $\mathrm{w} \neq \mathrm{y}$;

(ii) $v_{\mathrm{i}}^{2}(\mathrm{y})=\alpha_{\mathrm{i}}^{(1)}$.

By Weak Pareto Criterion $\mathrm{F}\left(\mathrm{V}^{(2)}\right) \subset\{\mathrm{x}, \mathrm{y}\}$.

Since $\mathrm{V}^{(2)}$ is obtained via a binary transfer from $\mathrm{V}^{(1)}$ at $\mathrm{y}$ and $\mathrm{y} \notin \mathrm{F}\left(\mathrm{V}^{(1)}\right), \mathrm{y} \notin \mathrm{F}\left(\mathrm{V}^{(2)}\right)$ since $\mathrm{F}$ is strongly insensitive to binary transfers.

Thus, $\mathrm{F}\left(\mathrm{V}^{(2)}\right)=\{\mathrm{x}\}$.

Case 2: $\alpha_{1}-\mathrm{u}_{1}(\mathrm{y})>\mathrm{u}_{2}(\mathrm{y})-\alpha_{2}$.

Consider the vector $\alpha^{(1)}=\left(\alpha_{1}-\left(u_{2}(y)-\alpha_{2}\right), u_{2}(y), \alpha_{3}, \ldots, \alpha_{n}\right)$.

Let $\mathrm{V}^{(2)}=\left(\mathrm{v}_{1}^{2}, \mathrm{v}_{2}^{2}, \ldots, \mathrm{v}_{\mathrm{n}}^{2}\right)$ be the evaluation profile such that:

(i) $\mathrm{v}_{\mathrm{i}}^{2}(\mathrm{w})=\mathrm{v}_{\mathrm{i}}^{1}(\mathrm{w})$ for all $\mathrm{i} \in \mathrm{N}$ and $\mathrm{w} \neq \mathrm{y}$;

(ii) $v_{i}^{2}(y)=\alpha_{i}^{(1)}$.

By Weak Pareto Criterion $\mathrm{F}\left(\mathrm{V}^{(2)}\right) \subset\{\mathrm{x}, \mathrm{y}\}$.

Since $\mathrm{V}^{(2)}$ is obtained via a binary transfer from $\mathrm{V}^{(1)}$ at $\mathrm{y}$ and $\mathrm{y} \notin \mathrm{F}\left(\mathrm{V}^{(1)}\right), \mathrm{y} \notin \mathrm{F}\left(\mathrm{V}^{(2)}\right)$ since $\mathrm{F}$ is strongly insensitive to binary transfers.

Thus, $\mathrm{F}\left(\mathrm{V}^{(2)}\right)=\{\mathrm{x}\}$.

If $\mathrm{v}_{\mathrm{i}}^{2}(\mathrm{y})=\mathrm{u}_{\mathrm{i}}(\mathrm{y})$ for all $\mathrm{i} \in \mathrm{N}$, then, combined with $\mathrm{v}_{\mathrm{i}}^{2}(\mathrm{x})=\mathrm{u}_{\mathrm{i}}(\mathrm{x})$ for all $\mathrm{i} \in \mathrm{N}$ and $\mathrm{F}\left(\mathrm{V}^{(2)}\right)=\{\mathrm{x}\}$, IIA implies $\mathrm{y} \notin \mathrm{F}(\mathrm{U})$.

Hence suppose that it is not the case that $v_{i}^{2}(y)=u_{i}(y)$ for all $i \in N$. Notice that $\left(v_{1}^{2}(y), v_{2}^{2}(y), \ldots, v_{n}^{2}(y)\right)$ has at least one more coordinate equal to the corresponding coordinate of $\left(\mathrm{u}_{1}(\mathrm{y}), \mathrm{u}_{2}(\mathrm{y}), \ldots, \mathrm{u}_{\mathrm{n}}(\mathrm{y})\right)$ than $\left(\alpha_{1}, \ldots, \alpha_{\mathrm{n}}\right)$. Let $\mathrm{A}_{2}=\left\{\mathrm{i} \mid \mathrm{v}_{\mathrm{i}}^{2}(\mathrm{y})>\mathrm{u}_{\mathrm{i}}(\mathrm{y})\right\}$ and $\mathrm{B}_{2}=\left\{\mathrm{i} \mid \mathrm{v}_{\mathrm{i}}^{2}(\mathrm{y})<\mathrm{u}_{\mathrm{i}}(\mathrm{y})\right\}$. Clearly, $\mathrm{A}_{2}, \mathrm{~B}_{2} \neq \phi$. 
As before we can obtain an evaluation profile $\mathrm{V}^{(3)}=\left(\mathrm{v}_{1}^{3}, \mathrm{v}_{2}^{3}, \ldots, \mathrm{v}_{\mathrm{n}}^{3}\right)$ which is obtained via a binary transfer from $\mathrm{V}^{(2)}$ at $\mathrm{y}$.

By Weak Pareto Criterion $\mathrm{F}\left(\mathrm{V}^{(3)}\right) \subset\{\mathrm{x}, \mathrm{y}\}$.

Since $\mathrm{y} \notin \mathrm{F}\left(\mathrm{V}^{(2)}\right)$ and $\mathrm{F}$ is strongly insensitive to binary transfers it must be the case that $\mathrm{y} \notin \mathrm{F}\left(\mathrm{V}^{(3)}\right)$.

Thus, $\mathrm{F}\left(\mathrm{V}^{(2)}\right)=\{\mathrm{x}\}$.

If $\mathrm{v}_{\mathrm{i}}^{3}(\mathrm{y})=\mathrm{u}_{\mathrm{i}}(\mathrm{y})$ for all $\mathrm{i} \in \mathrm{N}$, then, combined with $\mathrm{v}_{\mathrm{i}}^{3}(\mathrm{x})=\mathrm{u}_{\mathrm{i}}(\mathrm{x})$ for all $\mathrm{i} \in \mathrm{N}$ and $\mathrm{F}\left(\mathrm{V}^{(3)}\right)=\{\mathrm{x}\}$, IIA implies $\mathrm{y} \notin \mathrm{F}(\mathrm{U})$.

Notice that $\left(\mathrm{v}_{1}^{3}(\mathrm{y}), \mathrm{v}_{2}^{3}(\mathrm{y}), \ldots, \mathrm{v}_{\mathrm{n}}^{3}(\mathrm{y})\right)$ has at least one more coordinate equal to the corresponding coordinate of $\left(\mathrm{u}_{1}(\mathrm{y}), \mathrm{u}_{2}(\mathrm{y}), \ldots, \mathrm{u}_{\mathrm{n}}(\mathrm{y})\right)$ than $\left(\mathrm{v}_{1}^{2}(\mathrm{y}), \mathrm{v}_{2}^{2}(\mathrm{y}), \ldots, \mathrm{v}_{\mathrm{n}}^{2}(\mathrm{y})\right)$.

Since the number of criteria/states of nature/voters is finite we come to a first positive integer $\mathrm{K}$ such that for the evaluation profile $\mathrm{V}^{(\mathrm{K})}=\left(\mathrm{v}_{1}^{\mathrm{K}}, \mathrm{v}_{2}^{\mathrm{K}}, \ldots, \mathrm{v}_{\mathrm{n}}^{\mathrm{K}}\right), \mathrm{y} \notin \mathrm{F}\left(\mathrm{V}^{(\mathrm{K})}\right), \mathrm{v}_{\mathrm{i}}^{\mathrm{K}}(\mathrm{x})=\mathrm{u}_{\mathrm{i}}(\mathrm{x}), \mathrm{v}_{\mathrm{i}}^{\mathrm{K}}(\mathrm{y})=\mathrm{u}_{\mathrm{i}}(\mathrm{y})$ for all $\mathrm{i} \in \mathrm{N}$ and $\{\mathrm{x}\}=$ $\mathrm{F}\left(\mathrm{V}^{(\mathrm{K})}\right)$.

By IIA we get $y \notin F(U)$.

Thus, $\mathrm{F}(\mathrm{U}) \subset \operatorname{Argmax}_{\mathrm{w}} \times \sum_{\mathrm{i}=1}^{\mathrm{n}} \mathrm{u}_{\mathrm{i}}(\mathrm{w})$.

Now we need to show that for all $U=\left(\mathrm{u}_{1}, \mathrm{u}_{2}, \ldots, \mathrm{u}_{\mathrm{n}}\right), \operatorname{Argmax}_{\mathrm{w} \in \mathrm{X}} \sum_{\mathrm{i}=1}^{\mathrm{n}} \mathrm{u}_{\mathrm{i}}(\mathrm{w}) \subset \mathrm{F}(\mathrm{U})$.

Let $\mathrm{x} \in \operatorname{Argmax}_{\mathrm{w} \in \mathrm{X}} \sum_{\mathrm{i}=1}^{\mathrm{n}} \mathrm{u}_{\mathrm{i}}(\mathrm{w})$. We have to show that $\mathrm{x} \in \mathrm{F}(\mathrm{U})$. Suppose not, i.e. $\mathrm{x} \notin \mathrm{F}(U)$. Clearly, $\mathrm{F}(\mathrm{U})$

$\subset\left\{\operatorname{Argmax}_{\mathrm{w} \in \mathrm{X}} \sum_{\mathrm{i}=1}^{\mathrm{n}} \mathrm{u}_{\mathrm{i}}(\mathrm{w})\right\} \backslash\{\mathrm{x}\} \neq \phi$. Let $\mathrm{y} \in \mathrm{F}(\mathrm{U})$.

Let $\mathrm{V}=\left(\mathrm{v}_{1}, \mathrm{v}_{2}, \ldots, \mathrm{v}_{\mathrm{n}}\right)$ be the evaluation profile such that:

(i) $v_{i}(x)=u_{i}(x), v_{i}(y)=u_{i}(y)$ for all $i \in N$.

(ii) for all $w \in X \backslash\{x, y\}, v_{i}(w)<\min \left\{u_{i}(x), u_{i}(y)\right\}$ for all $i \in N$.

By Weak Pareto $F(V) \subset\{x, y\}$.

If $\mathrm{x} \in \mathrm{F}(\mathrm{V})$, then along with $\mathrm{v}_{\mathrm{i}}(\mathrm{x})=\mathrm{u}_{\mathrm{i}}(\mathrm{x}), \mathrm{v}_{\mathrm{i}}(\mathrm{y})=\mathrm{u}_{\mathrm{i}}(\mathrm{y})$ for all $\mathrm{i} \in \mathrm{N}, \mathrm{y} \in \mathrm{F}(\mathrm{U})$ and $\mathrm{x} \notin \mathrm{F}(\mathrm{U})$, we get a violation of IIA.

Hence $\mathrm{x} \notin \mathrm{F}(\mathrm{V})$. Thus, $\mathrm{F}(\mathrm{V})=\{\mathrm{y}\}$.

If $\mathrm{u}_{\mathrm{i}}(\mathrm{y})=\mathrm{u}_{\mathrm{i}}(\mathrm{x})$ for all $\mathrm{i} \in \mathrm{N}$, then $\mathrm{y} \notin \mathrm{F}(\mathrm{U})$ by Pareto Indifference. Hence suppose $\left\{\mathrm{i} \in \mathrm{N} \mid \mathrm{u}_{\mathrm{i}}(\mathrm{y}) \neq \mathrm{u}_{\mathrm{i}}(\mathrm{x})\right\} \neq \phi$.

Let $\mathrm{A}_{1}=\left\{\mathrm{i} \mid \mathrm{u}_{\mathrm{i}}(\mathrm{x})>\mathrm{u}_{\mathrm{i}}(\mathrm{y})\right\}$ and $\mathrm{B}_{1}=\left\{\mathrm{i} \mid \mathrm{u}_{\mathrm{i}}(\mathrm{x})<\mathrm{u}_{\mathrm{i}}(\mathrm{y})\right\}$. Clearly, $\mathrm{A}_{1}, \mathrm{~B}_{1} \neq \phi$. Without loss of generality suppose

$1 \in \mathrm{A}_{1}, 2 \in \mathrm{B}_{1}$.

Case 1: $\mathrm{u}_{1}(\mathrm{x})-\mathrm{u}_{1}(\mathrm{y}) \leq \mathrm{u}_{2}(\mathrm{y})-\mathrm{u}_{2}(\mathrm{x})$.

Consider the vector $\alpha^{(1)}=\left(u_{1}(y), u_{2}(x)+\left(u_{1}(x)-u_{1}(y)\right), u_{3}(x), \ldots, u_{n}(x)\right)$.

Let $\mathrm{V}^{(1)}=\left(\mathrm{v}_{1}^{1}, \mathrm{v}_{2}^{1}, \ldots, \mathrm{v}_{\mathrm{n}}^{1}\right)$ be the evaluation profile such that:

(i) $\mathrm{v}_{\mathrm{i}}^{1}(\mathrm{w})=\mathrm{v}_{\mathrm{i}}(\mathrm{w})$ for all $\mathrm{i} \in \mathrm{N}$ and $\mathrm{w} \neq \mathrm{x}$;

(ii) $\mathrm{v}_{\mathrm{i}}^{1}(\mathrm{x})=\alpha_{\mathrm{i}}^{(1)}$.

Since $\mathrm{F}$ is strongly insensitive to binary transfers and $\mathrm{V}^{(1)}$ is obtained via a binary transfer from $\mathrm{V}$ at $\mathrm{x}$, it follows that $\mathrm{x} \notin \mathrm{F}\left(\mathrm{V}^{(1)}\right)$.

By Weak Pareto criterion $\mathrm{F}\left(\mathrm{V}^{(1)}\right) \subset\{\mathrm{x}, \mathrm{y}\}$.

Thus, $\mathrm{F}\left(\mathrm{V}^{(1)}\right)=\{\mathrm{y}\}$.

If $\mathrm{v}_{\mathrm{i}}^{1}(\mathrm{x})=\mathrm{u}_{\mathrm{i}}(\mathrm{y})=\mathrm{v}_{\mathrm{i}}^{1}(\mathrm{y})$ for all $\mathrm{i} \in \mathrm{N}$, then $\mathrm{x} \notin \mathrm{F}\left(\mathrm{V}^{(1)}\right)$ and Pareto-indifference implies $\mathrm{y}^{1} \notin \mathrm{F}\left(\mathrm{V}^{(1)}\right)$ leading to a contradiction.

Hence suppose $\left\{\mathrm{i} \in \mathrm{N} \mid \mathrm{v}_{\mathrm{i}}^{1}(\mathrm{y}) \neq \mathrm{v}_{\mathrm{i}}^{1}(\mathrm{x})\right\} \neq \phi$.

Notice that $\left(\mathrm{v}_{1}^{1}(\mathrm{x}), \mathrm{v}_{2}^{1}(\mathrm{x}), \ldots, \mathrm{v}_{\mathrm{n}}^{1}(\mathrm{x})\right)$ has at least one more coordinate equal to the corresponding coordinates of $\left(\mathrm{u}_{1}(\mathrm{y}), \mathrm{u}_{2}(\mathrm{y}), \ldots, \mathrm{u}_{\mathrm{n}}(\mathrm{y})\right)$ than $\left(\mathrm{u}_{1}(\mathrm{x}), \ldots, \mathrm{u}_{\mathrm{n}}(\mathrm{x})\right)$.

Case 2: $u_{1}(x)-u_{1}(y)>u_{2}(y)-u_{2}(x)$.

Consider the vector $\alpha^{(1)}=\left(\mathrm{u}_{1}(\mathrm{x})-\left(\mathrm{u}_{2}(\mathrm{y})-\mathrm{u}_{2}(\mathrm{x})\right), \mathrm{u}_{2}\left(\mathrm{y}^{1}\right), \mathrm{u}_{3}(\mathrm{x}), \ldots, \mathrm{u}_{\mathrm{n}}(\mathrm{x})\right)$.

Let $\mathrm{V}^{(1)}=\left(\mathrm{v}_{1}^{1}, \mathrm{v}_{2}^{1}, \ldots, \mathrm{v}_{\mathrm{n}}^{1}\right)$ be the evaluation profile such that:

(i) $v_{i}^{1}(w)=v_{i}(w)$ for all $i \in N$ and $w \neq x$;

(ii) $\mathrm{v}_{\mathrm{i}}^{1}(\mathrm{x})=\alpha_{\mathrm{i}}^{(1)}$.

Since $\mathrm{F}$ is strongly insensitive to binary transfers and $\mathrm{V}^{(1)}$ is obtained via a binary transfer from $\mathrm{V}$ at $\mathrm{x}$, it follows that $\mathrm{x} \notin \mathrm{F}\left(\mathrm{V}^{(1)}\right)$.

By Weak Pareto criterion $\mathrm{F}\left(\mathrm{V}^{(1)}\right) \subset\{\mathrm{x}, \mathrm{y}\}$.

Thus, $\mathrm{F}\left(\mathrm{V}^{(1)}\right)=\{\mathrm{y}\}$.

If $\mathrm{v}_{\mathrm{i}}^{1}(\mathrm{x})=\mathrm{u}_{\mathrm{i}}(\mathrm{y})=\mathrm{v}_{\mathrm{i}}^{1}(\mathrm{y})$ for all $\mathrm{i} \in \mathrm{N}$, then $\mathrm{x} \notin \mathrm{F}\left(\mathrm{V}^{(1)}\right)$ and Pareto-indifference implies $\mathrm{y}^{1} \notin \mathrm{F}\left(\mathrm{V}^{(1)}\right)$ leading to a contradiction.

Hence suppose $\left\{\mathrm{i} \in \mathrm{N} \mid \mathrm{v}_{\mathrm{i}}^{1}(\mathrm{y}) \neq \mathrm{v}_{\mathrm{i}}^{1}(\mathrm{x})\right\} \neq \phi$. 
Notice that $\left(v_{1}^{1}(x), v_{2}^{1}(x), \ldots, v_{n}^{1}(x)\right)$ has at least one more coordinate equal to the corresponding coordinates of $\left(\mathrm{u}_{1}(\mathrm{y}), \mathrm{u}_{2}(\mathrm{y}), \ldots, \mathrm{u}_{\mathrm{n}}(\mathrm{y})\right)$ than $\left(\mathrm{u}_{1}(\mathrm{x}), \ldots, \mathrm{u}_{\mathrm{n}}(\mathrm{x})\right)$.

Let $\mathrm{A}_{2}=\left\{\mathrm{i} \mid \mathrm{v}_{\mathrm{i}}^{1}(\mathrm{x})>\mathrm{v}_{\mathrm{i}}^{1}(\mathrm{y})\right\}$ and $\mathrm{B}_{2}=\left\{\mathrm{i} \mid \mathrm{v}_{\mathrm{i}}^{1}(\mathrm{x})<\mathrm{v}_{\mathrm{i}}^{1}(\mathrm{y})\right\}$. Clearly, $\mathrm{A}_{2}, \mathrm{~B}_{2} \neq \phi$.

As before we can obtain an evaluation profile $\mathrm{V}^{(2)}=\left(\mathrm{v}_{1}^{2}, \mathrm{v}_{2}^{2}, \ldots, \mathrm{v}_{\mathrm{n}}^{2}\right)$ which is obtained via a binary transfer from $\mathrm{V}^{(1)}$ at $\mathrm{x}$. Namely,
(i) $\mathrm{v}_{\mathrm{i}}^{2}(\mathrm{w})=\mathrm{v}_{\mathrm{i}}^{1}(\mathrm{w})$ for all $\mathrm{i} \in \mathrm{N}$ and $\mathrm{w} \neq \mathrm{x}$;
(ii) $\mathrm{v}_{\mathrm{i}}^{2}(\mathrm{x})=\alpha_{\mathrm{i}}^{(2)}$

where for some $k \in A_{2}$ and $h \in B_{2}, \alpha_{i}^{(2)}=v_{i}^{1}(x)$ if $i \notin\{k, h\}, \alpha_{k}^{(2)}=u_{k}(y), \alpha_{h}^{(2)}=u_{h}(y)+\left(v_{k}^{1}(x)-u_{k}(y)\right)$ if $v_{k}^{1}(x)-$ $u_{\mathrm{k}}(\mathrm{y}) \leq \mathrm{u}_{\mathrm{h}}(\mathrm{y})-\mathrm{v}_{\mathrm{h}}^{1}(\mathrm{x})$; and $\alpha_{\mathrm{k}}^{(2)}=\mathrm{u}_{\mathrm{k}}(\mathrm{y})-\left(\mathrm{u}_{\mathrm{h}}(\mathrm{y})-\mathrm{v}_{\mathrm{h}}^{1}(\mathrm{x})\right), \alpha_{\mathrm{h}}^{(2)}=\mathrm{u}_{\mathrm{h}}(\mathrm{y})$ if $\mathrm{v}_{\mathrm{k}}^{1}(\mathrm{x})-\mathrm{u}_{\mathrm{k}}(\mathrm{y})>\mathrm{u}_{\mathrm{h}}(\mathrm{y})-\mathrm{v}_{\mathrm{h}}^{1}(\mathrm{x})$.

By Weak Pareto criterion $\mathrm{F}\left(\mathrm{V}^{(2)}\right) \subset\{\mathrm{x}, \mathrm{y}\}$.

Since $\mathrm{F}$ is strongly insensitive to binary transfers and $\mathrm{V}^{(2)}$ is obtained via a binary transfer from $\mathrm{V}^{(1)}$ at $\mathrm{x}$, it follows that $\mathrm{x} \notin \mathrm{F}\left(\mathrm{V}^{(2)}\right)$.

If $\mathrm{v}_{\mathrm{i}}^{2}(\mathrm{x})=\mathrm{u}_{\mathrm{i}}(\mathrm{y})=\mathrm{v}_{\mathrm{i}}^{2}(\mathrm{y})$ for all $\mathrm{i} \in \mathrm{N}$, then $\mathrm{x} \notin \mathrm{F}\left(\mathrm{V}^{(2)}\right)$ and Pareto-indifference implies $\mathrm{y} \notin \mathrm{F}\left(\mathrm{V}^{(2)}\right)$. Thus, $\mathrm{F}\left(\mathrm{V}^{(2)}\right)=$ $\phi$, leading to a contradiction. Thus, $\left\{\mathrm{i} \in \mathrm{N} \mid \mathrm{v}_{\mathrm{i}}^{2}(\mathrm{x}) \neq \mathrm{u}_{\mathrm{i}}(\mathrm{y})\right\} \neq \phi$.

Having obtained $\mathrm{V}^{(\mathrm{r})}=\left(\mathrm{v}_{1}^{\mathrm{r}}, \mathrm{v}_{2}^{\mathrm{r}}, \ldots, \mathrm{v}_{\mathrm{n}}^{\mathrm{r}}\right)$ for $\mathrm{r}>1$ and $\mathrm{x} \notin \mathrm{F}\left(\mathrm{V}^{(\mathrm{r})}\right)$, where:

(i) $v_{i}^{r}(w)=v_{i}^{r-1}(w)$ for all $i \in N$ and $w \neq x$;

(ii) $v_{i}^{r}(x)=\alpha_{i}^{(r)}$

there are two possibilities:

(i) $v_{i}^{r}(x)=u_{i}(y)=v_{i}^{r}(y)$ for all $i \in N$;

(ii) $\left\{\mathrm{i} \in \mathrm{N} \mid \mathrm{v}_{\mathrm{i}}^{\mathrm{r}}\left(\mathrm{y}^{1}\right) \neq \mathrm{v}_{\mathrm{i}}^{\mathrm{r}}(\mathrm{x})\right\} \neq \phi$.

In the first case, by Pareto Indifference $\mathrm{y}^{1} \notin \mathrm{F}\left(\mathrm{V}^{(\mathrm{r})}\right)$.

In the second case, let $\mathrm{A}_{\mathrm{r}+1}=\left\{\mathrm{i} \mid \mathrm{v}_{\mathrm{i}}^{\mathrm{r}}(\mathrm{x})>\mathrm{v}_{\mathrm{i}}^{\mathrm{r}}(\mathrm{y})\right\}$ and $\mathrm{B}_{\mathrm{r}+1}=\left\{\mathrm{i} \mid \mathrm{v}_{\mathrm{i}}^{\mathrm{r}}(\mathrm{x})<\mathrm{v}_{\mathrm{i}}^{\mathrm{r}}(\mathrm{y})\right\}$. Clearly, $\mathrm{A}_{\mathrm{r}+1}, \mathrm{~B}_{\mathrm{r}+1} \neq \phi$.

As before we can obtain an evaluation profile $\mathrm{V}^{(\mathrm{r}+1)}=\left(\mathrm{v}_{1}^{\mathrm{r}+1}, \mathrm{v}_{2}^{\mathrm{r}+1}, \ldots, \mathrm{v}_{\mathrm{n}}^{\mathrm{r}+1}\right)$ which is obtained via a binary transfer from $\mathrm{V}^{(\mathrm{r})}$ at $\mathrm{x}$. Namely,

(i) $v_{i}^{r+1}(w)=u_{i}(w)$ for all $i \in N$ and $w \neq x$;

(ii) $v_{i}^{r+1}(x)=\alpha_{i}^{(r+1)}$

where for some $k \in A_{r+1}$ and $h \in B_{r+1}, \alpha_{i}^{(r+1)}=v_{i}^{r+1}(x)$ if i $\notin\{k, h\}, \alpha_{k}^{(r+1)}=u_{k}(y), \alpha_{h}^{(r+1)}=u_{h}(y)+\left(v_{k}^{r}(x)-u_{k}(y)\right)$ if $v_{k}^{r}(x)-u_{k}(y) \leq u_{h}(y)-v_{h}^{r}(x)$; and $\alpha_{k}^{(r+1)}=u_{k}(y)-\left(u_{h}(y)-v_{h}^{r}(x)\right), \alpha_{h}^{(r+1)}=u_{h}(y)$ if $v_{k}^{r}(x)-u_{k}(y)>u_{h}(y)-v_{h}^{r}(x)$.

Since the number of criteria/states of nature/voters is finite we come to a first positive integer $\mathrm{K}$ such that for the evaluation profile $\mathrm{V}^{(\mathrm{K})}=\left(\mathrm{v}_{1}^{\mathrm{K}}, \mathrm{v}_{2}^{\mathrm{K}}, \ldots, \mathrm{v}_{\mathrm{n}}^{\mathrm{K}}\right), \mathrm{v}_{\mathrm{i}}^{\mathrm{K}}(\mathrm{x})=\mathrm{u}_{\mathrm{i}}(\mathrm{y})=\mathrm{v}_{\mathrm{i}}^{\mathrm{K}}(\mathrm{y})$ for all $\mathrm{i} \in \mathrm{N}$ and $\mathrm{x} \notin \mathrm{F}\left(\mathrm{V}^{(\mathrm{K})}\right)$ since $\mathrm{F}$ is strongly insensitive to binary transfers and $\mathrm{V}^{(\mathrm{K})}$ is obtained via a binary transfer from $\mathrm{V}^{(\mathrm{K}-1)}$ at $\mathrm{x}$. By Pareto Indifference, $\mathrm{y} \notin \mathrm{F}\left(\mathrm{V}^{(\mathrm{K})}\right)$.

However by Weak Pareto criterion, $\mathrm{F}\left(\mathrm{V}^{(\mathrm{K})}\right) \subset\{\mathrm{x}, \mathrm{y}\}$. Thus, $\mathrm{F}\left(\mathrm{V}^{(\mathrm{K})}\right)=\phi$, leading to a contradiction.

Hence $x \in F(U)$, i.e. $F$ is the utilitarian social choice functional. Q.E.D.

Here is a second axiomatic characterization.

Proposition 2: The only social choice functional on $\mathcal{U}^{\mathrm{n}}$ that satisfies the Weak Pareto criterion, Pareto indifference, IIA and treats binary variants almost equally is the utilitarian SCFL.

Proof: It is easy to see that the utilitarian SCFL satisfies the desired properties. Hence let F be an SCFL on $\mathcal{U}^{\mathrm{n}}$ that satisfies the Weak Pareto criterion, Pareto indifference, IIA and treats binary variants almost equally. It follows from lemma 1, that F satisfies SN. Further by lemma 3, we get that F treats binary invariants equally. We need to show that it is the utilitarian SCFL.

Let $\mathrm{U}=\left(\mathrm{u}_{1}, \mathrm{u}_{2}, \ldots, \mathrm{u}_{\mathrm{n}}\right)$ be an evaluation profile and let $\mathrm{x}, \mathrm{y} \in \mathrm{X}$ with $\sum_{\mathrm{i}=1}^{\mathrm{n}} \mathrm{u}_{\mathrm{i}}(\mathrm{x})>\sum_{\mathrm{i}=1}^{\mathrm{n}} \mathrm{u}_{\mathrm{i}}(\mathrm{y})$. Let us show that $\mathrm{y} \notin \mathrm{F}(\mathrm{U})$.

If $\mathrm{u}_{\mathrm{i}}(\mathrm{x})>\mathrm{u}_{\mathrm{i}}(\mathrm{y})$ for all $\mathrm{i} \in \mathrm{N}$, then by the Weak Pareto criterion $\mathrm{y} \notin \mathrm{F}(\mathrm{U})$ and we are done. Hence suppose that it is not the case that $\left[u_{i}(x)>u_{i}(y)\right.$ for all $\left.i \in N\right]$.

Let $\alpha=\left(\alpha_{1}, \ldots, \alpha_{n}\right)$ be a point in $\mathbb{R}^{n}$ such that $\mathrm{u}_{\mathrm{i}}(\mathrm{x})>\alpha_{\mathrm{i}}$ for all $\mathrm{i} \in \mathrm{N}$ and $\sum_{\mathrm{i}=1}^{\mathrm{n}} \alpha_{\mathrm{i}}=\sum_{\mathrm{i}=1}^{\mathrm{n}} \mathrm{u}_{\mathrm{i}}(\mathrm{y})$. For instance $\alpha_{\mathrm{i}}=$ $\mathrm{u}_{\mathrm{i}}(\mathrm{x})-\frac{\sum_{\mathrm{i}=1}^{\mathrm{n}} \mathrm{u}_{\mathrm{i}}(\mathrm{x})-\sum_{\mathrm{i}=1}^{\mathrm{n}} \mathrm{u}_{\mathrm{i}}(\mathrm{y})}{\mathrm{n}}$ for all $\mathrm{i} \in \mathrm{N}$, would serve our purpose. Clearly $\alpha \neq\left(\mathrm{u}_{1}(\mathrm{y}), \ldots, \mathrm{u}_{\mathrm{n}}(\mathrm{y})\right)$.

Let $\mathrm{A}_{1}=\left\{\mathrm{i} \mid \alpha_{\mathrm{i}}>\mathrm{u}_{\mathrm{i}}(\mathrm{y})\right\}$ and $\mathrm{B}_{1}=\left\{\mathrm{i} \mid \alpha_{\mathrm{i}}<\mathrm{u}_{\mathrm{i}}(\mathrm{y})\right\}$. Clearly, $\mathrm{A}_{1}, \mathrm{~B}_{1} \neq \phi$. Without loss of generality suppose $1 \in \mathrm{A}_{1}$, $2 \in \mathrm{B}_{1}$.

Case 1: $\alpha_{1}-\mathrm{u}_{1}(\mathrm{y}) \leq \mathrm{u}_{2}(\mathrm{y})-\alpha_{2}$.

Consider the vector $\alpha^{(1)}=\left(u_{1}(y), \alpha_{2}+\left(\alpha_{1}-u_{1}(y)\right), \alpha_{3}, \ldots, \alpha_{n}\right)$. 
Let $\mathrm{z} \in \mathrm{X} \backslash\{\mathrm{x}, \mathrm{y}\}$ and consider the evaluation profile $\mathrm{V}^{(1)}=\left(\mathrm{v}_{1}^{1}, \mathrm{v}_{2}^{1}, \ldots, \mathrm{v}_{\mathrm{n}}^{1}\right)$ where:

(i) $v_{\mathrm{i}}^{1}(\mathrm{x})=\mathrm{u}_{\mathrm{i}}(\mathrm{x})$ for all $\mathrm{i} \in \mathrm{N}$;

(ii) $v_{\mathrm{i}}^{1}(\mathrm{z})=\alpha_{\mathrm{i}}$ for all $\mathrm{i} \in \mathrm{N}$;

(iii) $v_{i}^{1}(y)=\alpha_{i}^{(1)}$ for all $i \in N$

(iv) $v_{i}^{1}(w)<u_{i}(x)$ for all $i \in N$ and $w \in X \backslash\{x, y, z\}$.

By Weak Pareto $\mathrm{F}\left(\mathrm{V}^{(1)}\right) \subset\{\mathrm{x}, \mathrm{y}\}$.

Since $y$ is a binary variant of $\mathrm{z}$ and $\mathrm{F}$ treats binary variants equally, the fact that $\mathrm{z} \notin \mathrm{F}\left(\mathrm{V}^{(1)}\right)$ implies $\mathrm{y} \notin \mathrm{F}\left(\mathrm{V}^{(1)}\right)$.

Thus, $\{\mathrm{x}\}=\mathrm{F}\left(\mathrm{V}^{(1)}\right)$.

Case 2: $\alpha_{1}-\mathrm{u}_{1}(\mathrm{y})>\mathrm{u}_{2}(\mathrm{y})-\alpha_{2}$.

Consider the vector $\alpha^{(1)}=\left(\alpha_{1}-\left(\mathrm{u}_{2}(\mathrm{y})-\alpha_{2}\right), \mathrm{u}_{2}(\mathrm{y}), \alpha_{3}, \ldots, \alpha_{\mathrm{n}}\right)$.

Let $\mathrm{z} \in \mathrm{X} \backslash\{\mathrm{x}, \mathrm{y}\}$ and consider the evaluation profile $\mathrm{V}^{(1)}=\left(\mathrm{v}_{1}^{1}, \mathrm{v}_{2}^{1}, \ldots, \mathrm{v}_{\mathrm{n}}^{1}\right)$ where:

(i) $v_{i}^{1}(x)=u_{i}(x)$ for all $i \in N$;

(ii) $v_{\mathrm{i}}^{1}(\mathrm{z})=\alpha_{\mathrm{i}}$ for all $\mathrm{i} \in \mathrm{N}$;

(iii) $v_{\mathrm{i}}^{1}(\mathrm{y})=\alpha_{\mathrm{i}}^{(1)}$ for all $\mathrm{i} \in \mathrm{N}$

(iv) $v_{i}^{1}(w)<u_{i}(x)$ for all $i \in N$ and $w \in X \backslash\{x, y, z\}$.

By Weak Pareto $\mathrm{F}\left(\mathrm{V}^{(1)}\right) \subset\{\mathrm{x}, \mathrm{y}\}$.

Since $y$ is a binary variant of $z$ and $F$ treats binary variants equally, the fact that $z \notin F\left(V^{(1)}\right)$ implies $y \notin F\left(V^{(1)}\right)$. Thus, $\{\mathrm{x}\}=\mathrm{F}\left(\mathrm{V}^{(1)}\right)$.

If $v_{i}^{1}(y)=u_{i}(y)$ for all $i \in N$, then, combined with $v_{i}^{1}(x)=u_{i}(x)$ for all $i \in N$ and $F\left(V^{(1)}\right)=\{x\}$, IIA implies $y \notin F(U)$. Hence suppose that it is not the case that $v_{i}^{1}(y)=u_{i}(y)$ for all $i \in N$.

Notice that $\left(\mathrm{v}_{1}^{1}(\mathrm{y}), \mathrm{v}_{2}^{1}(\mathrm{y}), \ldots, \mathrm{v}_{\mathrm{n}}^{1}(\mathrm{y})\right)$ has at least one more coordinate equal to the corresponding coordinate of $\left(\mathrm{u}_{1}(\mathrm{y}), \mathrm{u}_{2}(\mathrm{y}), \ldots, \mathrm{u}_{\mathrm{n}}(\mathrm{y})\right)$ than $\left(\alpha_{1}, \ldots, \alpha_{\mathrm{n}}\right)$.

Let $\mathrm{A}_{2}=\left\{\mathrm{i} \mid \mathrm{v}_{\mathrm{i}}^{1}(\mathrm{y})>\mathrm{u}_{\mathrm{i}}(\mathrm{y})\right\}$ and $\mathrm{B}_{2}=\left\{\mathrm{i} \mid \mathrm{v}_{\mathrm{i}}^{1}(\mathrm{y})<\mathrm{u}_{\mathrm{i}}(\mathrm{y})\right\}$. Clearly, $\mathrm{A}_{2}, \mathrm{~B}_{2} \neq \phi$. Let $\mathrm{i} \in \mathrm{A}_{2}$ and $\mathrm{j} \in \mathrm{B}_{2}$.

If $v_{i}^{1}(y)-u_{i}(y) \leq u_{j}(y)-v_{j}^{1}(y)$, then let $\alpha^{(2)}$ be the n-vector such that $\alpha_{k}^{2}=v_{k}^{1}(y)$ for all $k \in N \backslash\{i, j\}, \alpha_{i}^{2}=u_{i}(y), \alpha_{j}^{2}$ $=v_{j}^{1}(y)+\left(v_{i}^{1}(y)-u_{i}(y)\right)$.

If $v_{i}^{1}(y)-u_{i}(y)>u_{j}(y)-v_{j}^{1}(y)$, then let $\alpha^{(2)}$ be the n-vector such that $\alpha_{k}^{2}=v_{k}^{1}(y)$ for all $k \in N \backslash\{i, j\}, \alpha_{i}^{2}=v_{i}^{1}(y)-$ $\left(u_{j}(y)-v_{j}^{1}(y)\right), \alpha_{j}^{2}=u_{j}(y)$.

Let $\mathrm{z} \in \mathrm{X} \backslash\{\mathrm{x}, \mathrm{y}\}$ and consider the evaluation profile $\mathrm{V}^{(2)}=\left(\mathrm{v}_{1}^{2}, \mathrm{v}_{2}^{2}, \ldots, \mathrm{v}_{\mathrm{n}}^{2}\right)$ where:

(i) $v_{\mathrm{k}}^{2}(\mathrm{x})=\mathrm{u}_{\mathrm{k}}(\mathrm{x})$ for all $\mathrm{k} \in \mathrm{N}$;

(ii) $\mathrm{v}_{\mathrm{k}}^{2}(\mathrm{z})=\mathrm{v}_{\mathrm{k}}^{1}(\mathrm{y})$ for all $\mathrm{k} \in \mathrm{N}$;

(iii) $\mathrm{v}_{\mathrm{k}}^{2}(\mathrm{y})=\alpha_{\mathrm{k}}^{2}$ for all $\mathrm{k} \in \mathrm{N}$;

(iv) $\mathrm{v}_{\mathrm{k}}^{2}(\mathrm{w})<\mathrm{u}_{\mathrm{k}}(\mathrm{x})$ for all $\mathrm{i} \in \mathrm{N}$ and $\mathrm{w} \in \mathrm{X} \backslash\{\mathrm{x}, \mathrm{y}, \mathrm{z}\}$.

By Weak Pareto criterion, $\mathrm{F}\left(\mathrm{V}^{(2)}\right) \subset\{\mathrm{x}, \mathrm{y}, \mathrm{z}\}$. By SN (which by Lemma 1 is implied by PI and IIA) and the facts that $F\left(V^{(1)}\right)=\{x\}, v_{k}^{2}(x)=u_{k}(x)$ for all $k \in N$ and $v_{k}^{2}(z)=v_{k}^{1}(y)$ for all $k \in N$, we get $z \notin F\left(V^{(2)}\right)$. Since $F$ treats binary variants equally, and $\mathrm{y}$ is a binary variant of $\mathrm{z}, \mathrm{y} \notin \mathrm{F}\left(\mathrm{V}^{(2)}\right)$. Thus, $\{\mathrm{x}\}=\mathrm{F}\left(\mathrm{V}^{(2)}\right)$.

If $v_{\mathrm{i}}^{2}(\mathrm{y})=\mathrm{u}_{\mathrm{i}}(\mathrm{y})$ for all $\mathrm{i} \in \mathrm{N}$, then, combined with $\mathrm{v}_{\mathrm{i}}^{1}(\mathrm{x})=\mathrm{u}_{\mathrm{i}}(\mathrm{x})$ for all $\mathrm{i} \in \mathrm{N}$ and $\mathrm{F}\left(\mathrm{V}^{(1)}\right)=\{\mathrm{x}\}$, IIA implies $\mathrm{y} \notin \mathrm{F}(\mathrm{U})$.

Since the number of criteria/states of nature/voters is finite we come to a first positive integer $\mathrm{K}$ such that for the evaluation profile $\mathrm{V}^{(\mathrm{K})}=\left(\mathrm{v}_{1}^{\mathrm{K}}, \mathrm{v}_{2}^{\mathrm{K}}, \ldots, \mathrm{v}_{\mathrm{n}}^{\mathrm{K}}\right), \mathrm{y} \notin \mathrm{F}\left(\mathrm{V}^{(\mathrm{K})}\right), \mathrm{v}_{\mathrm{i}}^{\mathrm{K}}(\mathrm{x})=\mathrm{u}_{\mathrm{i}}(\mathrm{x}), \mathrm{v}_{\mathrm{i}}^{\mathrm{K}}(\mathrm{y})=\mathrm{u}_{\mathrm{i}}(\mathrm{y})$ for all $\mathrm{i} \in \mathrm{N}$ and $\{\mathrm{x}\}=$ $\mathrm{F}\left(\mathrm{V}^{(\mathrm{K})}\right)$.

By IIA we get $\mathrm{y} \notin \mathrm{F}(\mathrm{U})$.

Thus, $\mathrm{F}(\mathrm{U}) \subset \operatorname{Argmax}_{\mathrm{w} \in \mathrm{X}} \sum_{\mathrm{i}=1}^{\mathrm{n}} \mathrm{u}_{\mathrm{i}}(\mathrm{w})$.

Now we need to show that for all $U=\left(u_{1}, u_{2}, \ldots, u_{n}\right), \operatorname{Argmax}_{w} x \sum_{i=1}^{n} u_{i}(w) \subset F(U)$.

Let $\mathrm{y} \in \operatorname{Argmax}_{\mathrm{w} \in \mathrm{x}} \sum_{\mathrm{i}=1}^{\mathrm{n}} \mathrm{u}_{\mathrm{i}}(\mathrm{w})$. We have to show that $\mathrm{y} \in \mathrm{F}(\mathrm{U})$. Suppose not, i.e. $\mathrm{y} \notin \mathrm{F}(\mathrm{U})$. Clearly, $F(U)$

$\subset\left\{\operatorname{Argmax}_{\mathrm{w} \in \mathrm{X}} \sum_{\mathrm{i}=1}^{\mathrm{n}} \mathrm{u}_{\mathrm{i}}(\mathrm{w})\right\} \backslash\{\mathrm{y}\} \neq \phi$. Let $\mathrm{x} \in \mathrm{F}(\mathrm{U})$.

If $u_{i}(x)=u_{i}(y)$ for all $i \in N$, then by Pareto indifference either both $x$ and $y$ belong to $F(U)$ or neither belong to $\mathrm{F}(\mathrm{U})$, leading to a contradiction.

Hence suppose $\left\{\mathrm{i} \in \mathrm{N} \mid \mathrm{u}_{\mathrm{i}}(\mathrm{x}) \neq \mathrm{u}_{\mathrm{i}}(\mathrm{y})\right\} \neq \phi$.

Let $\mathrm{A}_{1}=\left\{\mathrm{i} \in \mathrm{N} \mid \mathrm{u}_{\mathrm{i}}(\mathrm{y})>\mathrm{u}_{\mathrm{i}}(\mathrm{x})\right\}$ and $\mathrm{B}_{1}=\left\{\mathrm{i} \in \mathrm{N} \mid \mathrm{u}_{\mathrm{i}}(\mathrm{y})<\mathrm{u}_{\mathrm{i}}(\mathrm{x})\right\}$. Without loss of generality suppose $1 \in \mathrm{A}_{1}$ and $2 \in \mathrm{B}_{1}$. Let $\mathrm{z} \in \mathrm{X} \backslash\{\mathrm{x}, \mathrm{y}\}$.

Case 1: $\mathrm{u}_{1}(\mathrm{y})-\mathrm{u}_{1}(\mathrm{x}) \leq \mathrm{u}_{2}(\mathrm{x})-\mathrm{u}_{2}(\mathrm{y})$

Let $\beta^{(1)}=\left(u_{1}(x), u_{2}(y)+\left(u_{1}(y)-u_{1}(x)\right), u_{3}(y), \ldots, u_{n}(y)\right)$ 
Let $\mathrm{V}^{(1)}=\left(\mathrm{v}_{1}^{(1)}, \mathrm{v}_{2}^{(1)}, \ldots, \mathrm{v}_{\mathrm{n}}^{(1)}\right)$ be an evaluation profile such that:
(i) $v_{i}^{(1)}(x)=u_{i}(x), v_{i}^{(1)}(y)=u_{i}(y)$ for all $i \in N$.
(ii) $v_{i}^{(1)}(z)=\beta_{i}^{(1)}$ for all $i \in N$.
(iii) $\mathrm{v}_{\mathrm{i}}^{(1)}(\mathrm{w})=\min \left\{\mathrm{u}_{\mathrm{i}}(\mathrm{x}), \mathrm{u}_{\mathrm{i}}(\mathrm{y}), \beta_{\mathrm{i}}^{(1)}\right\}$ for all $\mathrm{w} \in \mathrm{X} \backslash\{\mathrm{x}, \mathrm{y}, \mathrm{z}\}$ and $\mathrm{i} \in \mathrm{N}$.

Case 2: $\mathrm{u}_{1}(\mathrm{y})-\mathrm{u}_{1}(\mathrm{x})>\mathrm{u}_{2}(\mathrm{x})-\mathrm{u}_{2}(\mathrm{y})$

Let $\beta^{(1)}=\left(\mathrm{u}_{1}(\mathrm{y})-\left(\mathrm{u}_{2}(\mathrm{x})-\mathrm{u}_{2}(\mathrm{y})\right), \mathrm{u}_{2}(\mathrm{x}), \mathrm{u}_{3}(\mathrm{y}), \ldots, \mathrm{u}_{\mathrm{n}}(\mathrm{y})\right)$

Let $\mathrm{V}^{(1)}=\left(\mathrm{v}_{1}^{(1)}, \mathrm{v}_{2}^{(1)}, \ldots, \mathrm{v}_{\mathrm{n}}^{(1)}\right)$ be an evaluation profile such that:

(i) $v_{i}^{(1)}(x)=u_{i}(x), v_{i}^{(1)}(y)=u_{i}(y)$ for all $i \in N$.

(ii) $v_{i}^{(1)}(z)=\beta_{i}^{(1)}$ for all $i \in N$.

(iii) $\mathrm{v}_{\mathrm{i}}^{(1)}(\mathrm{w})=\min \left\{\mathrm{u}_{\mathrm{i}}(\mathrm{x}), \mathrm{u}_{\mathrm{i}}(\mathrm{y}), \beta_{\mathrm{i}}^{(1)}\right\}$ for all $\mathrm{w} \in \mathrm{X} \backslash\{\mathrm{x}, \mathrm{y}, \mathrm{z}\}$ and $\mathrm{i} \in \mathrm{N}$.

$\left(v_{1}^{(1)}(z), v_{2}^{(1)}(z), \ldots, v_{n}^{(1)}(z)\right)$ has fewer coordinates unequal to $\left(u_{1}(x), \ldots, u_{n}(x)\right)$ than $\left(u_{1}(y), \ldots, u_{n}(y)\right)$ has.

By Weak Pareto criterion, $\mathrm{F}\left(\mathrm{V}^{(1)}\right) \subset\{\mathrm{x}, \mathrm{y}, \mathrm{z}\}$.

By IIA, $x \in F(U), y \notin F(U), v_{i}^{(1)}(x)=u_{i}(x), v_{i}^{(1)}(y)=u_{i}(y)$ for all $i \in N$ implies $y \notin F\left(V^{(1)}\right)$.

Since $\mathrm{z}$ is a binary invariant of $\mathrm{y}$ at $\mathrm{V}$, and since $\mathrm{F}$ treats binary invariants equally, $\mathrm{y} \notin \mathrm{F}\left(\mathrm{V}^{(1)}\right)$ implies $\mathrm{z} \notin \mathrm{F}\left(\mathrm{V}^{(1)}\right)$. Thus, $\mathrm{F}\left(\mathrm{V}^{(1)}\right)=\{\mathrm{x}\}$.

Suppose $v_{i}^{(1)}(x)=u_{i}(x)=v_{i}^{(1)}(z)$ for all $i \in N$. Then by Pareto indifference, either both $x$ and $z$ belong to $\mathrm{F}\left(\mathrm{V}^{(1)}\right)$ or neither does, contradicting $\mathrm{F}\left(\mathrm{V}^{(1)}\right)=\{\mathrm{x}\}$. Hence suppose, $\left\{\mathrm{i} \in \mathrm{N} \mid \mathrm{u}_{\mathrm{i}}(\mathrm{x}) \neq \mathrm{v}_{\mathrm{i}}^{(1)}(\mathrm{z})\right\} \neq \phi$.

Let $\mathrm{A}_{2}=\left\{\mathrm{i} \in \mathrm{N} \mid \mathrm{u}_{\mathrm{i}}(\mathrm{x})>\mathrm{v}_{\mathrm{i}}^{(1)}(\mathrm{z})\right\}$ and $\mathrm{B}_{2}=\left\{\mathrm{i} \in \mathrm{N} \mid \mathrm{u}_{\mathrm{i}}(\mathrm{x})<\mathrm{v}_{\mathrm{i}}^{(1)}(\mathrm{z})\right\}$. Let $\mathrm{h} \in \mathrm{A}_{2}$ and $\mathrm{j} \in \mathrm{B}_{2}$. Let the evaluation profile $\mathrm{V}^{(2)}=\left(\mathrm{v}_{1}^{(2)}, \mathrm{v}_{2}^{(2)}, \ldots, \mathrm{v}_{\mathrm{n}}^{(2)}\right)$ be defined as follows:

Case 1: $u_{h}(x)-v_{h}^{(1)}(z)>v_{j}^{(1)}(z)-u_{j}(x)$

Let $\beta_{\mathrm{i}}^{(2)}=\mathrm{v}_{\mathrm{i}}^{(1)}(\mathrm{z})$ for all $\mathrm{i} \notin\{\mathrm{h}, \mathrm{k}\}, \beta_{\mathrm{h}}^{(2)}=\mathrm{v}_{\mathrm{h}}^{(1)}(\mathrm{z})+\left(\mathrm{v}_{\mathrm{j}}^{(1)}(\mathrm{z})-\mathrm{u}_{\mathrm{j}}(\mathrm{x})\right), \beta_{\mathrm{j}}^{(2)}=\mathrm{u}_{\mathrm{j}}(\mathrm{x})$ and,

(i) $v_{i}^{(2)}(x)=u_{i}(x), v_{i}^{(2)}(y)=v_{i}^{(1)}(z)$ for all $i \in N$.

(ii) $v_{\mathrm{i}}^{(2)}(\mathrm{z})=\beta_{\mathrm{i}}^{(2)}$ for all $\mathrm{i} \in \mathrm{N}$.

(iii) $\mathrm{v}_{\mathrm{i}}^{(2)}(\mathrm{w})=\min \left\{\mathrm{u}_{\mathrm{i}}(\mathrm{x}), \mathrm{v}_{\mathrm{i}}^{(2)}(\mathrm{y}), \beta_{\mathrm{i}}^{(2)}\right\}$ for all $\mathrm{w} \in \mathrm{X} \backslash\{\mathrm{x}, \mathrm{y}, \mathrm{z}\}$ and $\mathrm{i} \in \mathrm{N}$.

Case 1: $u_{h}(x)-v_{h}^{(1)}(z) \leq v_{j}^{(1)}(z)-u_{j}(x)$

Let $\beta_{\mathrm{i}}^{(2)}=\mathrm{v}_{\mathrm{i}}^{(1)}(\mathrm{z})$ for all $\mathrm{i} \notin\{\mathrm{h}, \mathrm{k}\}, \beta_{\mathrm{h}}^{(2)}=\mathrm{u}_{\mathrm{h}}(\mathrm{x}), \beta_{\mathrm{j}}^{(2)}=\mathrm{v}_{\mathrm{j}}^{(1)}(\mathrm{z})-\left(\mathrm{u}_{\mathrm{h}}(\mathrm{x})-\mathrm{v}_{\mathrm{h}}^{(1)}(\mathrm{z})\right)$ and,

(i) $v_{i}^{(2)}(x)=u_{i}(x), v_{i}^{(2)}(y)=v_{i}^{(1)}(z)$ for all $i \in N$.

(ii) $v_{\mathrm{i}}^{(2)}(\mathrm{z})=\beta_{\mathrm{i}}^{(2)}$ for all $\mathrm{i} \in \mathrm{N}$.

(iii) $\mathrm{v}_{\mathrm{i}}^{(2)}(\mathrm{w})=\min \left\{\mathrm{u}_{\mathrm{i}}(\mathrm{x}), \mathrm{v}_{\mathrm{i}}^{(2)}(\mathrm{y}), \beta_{\mathrm{i}}^{(2)}\right\}$ for all $\mathrm{w} \in \mathrm{X} \backslash\{\mathrm{x}, \mathrm{y}, \mathrm{z}\}$ and $\mathrm{i} \in \mathrm{N}$.

$\left(v_{1}^{(2)}(\mathrm{z}), \mathrm{v}_{2}^{(2)}(\mathrm{z}), \ldots, \mathrm{v}_{\mathrm{n}}^{(2)}(\mathrm{z})\right)$ has fewer coordinates different from $\left(\mathrm{u}_{1}(\mathrm{x}), \ldots, \mathrm{u}_{\mathrm{n}}(\mathrm{x})\right)$ than

$\left(\mathrm{v}_{1}^{(1)}(\mathrm{z}), \mathrm{v}_{2}^{(1)}(\mathrm{z}), \ldots, \mathrm{v}_{\mathrm{n}}^{(1)}(\mathrm{z})\right)$.

By Weak Pareto criterion, $\mathrm{F}\left(\mathrm{V}^{(2)}\right) \subset\{\mathrm{x}, \mathrm{y}, \mathrm{z}\}$.

$\mathrm{x} \in \mathrm{F}\left(\mathrm{V}^{(1)}\right), \mathrm{z} \notin \mathrm{F}\left(\mathrm{V}^{(1)}\right), \mathrm{v}_{\mathrm{i}}^{(2)}(\mathrm{x})=\mathrm{u}_{\mathrm{i}}(\mathrm{x})=\mathrm{v}_{\mathrm{i}}^{(1)}(\mathrm{x}), \mathrm{v}_{\mathrm{i}}^{(2)}(\mathrm{y})=\mathrm{v}_{\mathrm{i}}^{(1)}(\mathrm{z})$ for all $\mathrm{i} \in \mathrm{N}$ and $\mathrm{SN}$ (which by lemma 1 is implied by PI and IIA) implies $\mathrm{y} \notin \mathrm{F}\left(\mathrm{V}^{(2)}\right)$. $\mathrm{z}$ is a binary variant of $\mathrm{y}$ and $\mathrm{F}$ treats binary variants equally implies $\mathrm{z} \notin \mathrm{F}\left(\mathrm{V}^{(2)}\right)$.

Since the number of criteria/states of nature/voters is finite we come to a first positive integer $\mathrm{K}$ such that for the evaluation profile $\mathrm{V}^{(\mathrm{K})}=\left(\mathrm{v}_{1}^{\mathrm{K}}, \mathrm{v}_{2}^{\mathrm{K}}, \ldots, \mathrm{v}_{\mathrm{n}}^{\mathrm{K}}\right), \mathrm{y} \notin \mathrm{F}\left(\mathrm{V}^{(\mathrm{K})}\right), \mathrm{z}$ is a binary variant of $\mathrm{y}, \mathrm{v}_{\mathrm{i}}^{\mathrm{K}}(\mathrm{z})=\mathrm{u}_{\mathrm{i}}(\mathrm{x})=\mathrm{v}_{\mathrm{i}}^{\mathrm{K}}(\mathrm{x})$ for all $i \in N$ and by Weak Pareto criterion $F\left(V^{(K)}\right) \subset\{x, y, z\}$. Since $z$ is a binary invariant of $y$ at $F$ treats binary variants equally, $\mathrm{z} \notin \mathrm{F}\left(\mathrm{V}^{(\mathrm{K})}\right)$. Thus, $\mathrm{F}\left(\mathrm{V}^{(\mathrm{K})}\right)=\{\mathrm{x}\}$. However, $\mathrm{v}_{\mathrm{i}}^{\mathrm{K}}(\mathrm{z})=\mathrm{u}_{\mathrm{i}}(\mathrm{x})=\mathrm{v}_{\mathrm{i}}^{\mathrm{K}}(\mathrm{x})$ and Pareto indifference implies either $\mathrm{x}$ and $\mathrm{z}$ both belong to $\mathrm{F}\left(\mathrm{V}^{(\mathrm{K})}\right)$ or neither does, leading to a contradiction.

Thus, $\mathrm{y} \in \mathrm{F}(\mathrm{U})$ and hence $\mathrm{F}$ is the utilitarian social choice functional. This proves the theorem. Q.E.D.

\section{WEIGHTED UTILITARIANISM}

Let $\Delta^{\mathrm{n}-1}=\left\{\lambda \in \mathbb{R}_{+}^{\mathrm{N}} \mid \sum_{\mathrm{i}=1}^{\mathrm{n}} \lambda_{\mathrm{i}}=1\right\}$ denote the $\mathrm{n}-1$ dimensional simplex.

An SCFL F on an admissible set $\mathcal{D}$ is said to satisfy Harsanyi's Weighted Utilitarianism (HWU) if for all $U$ $=\left(\mathrm{u}_{1}, \ldots, \mathrm{u}_{\mathrm{n}}\right) \in \mathcal{D}$, there exists $\lambda^{\mathrm{U}} \in \Delta^{\mathrm{n}-1}$ such that $\mathrm{F}(\mathrm{U}) \subset \operatorname{Argmax}_{\mathrm{x} \in \mathrm{X}} \sum_{\mathrm{i}=1}^{\mathrm{n}} \lambda_{\mathrm{i}}^{\mathrm{U}} \mathrm{u}_{\mathrm{i}}(\mathrm{x})$. 
ASCFL $\mathrm{F}$ on an admissible set $\mathcal{D}$ is said to satisfy Exact Harsanyi's Weighted Utilitarianism (E-HWU) if for all $U=\left(u_{1}, \ldots, u_{n}\right) \in \mathcal{D}$, there exists $\lambda^{U} \in \Delta^{n-1}$ such that $F(U)=\operatorname{Argmax}_{x \in X} \sum_{i=1}^{n} \lambda_{i}^{U} u_{i}(x)$.

An SCFL F on an admissible set $\mathcal{D}$ is said to satisfy the non-existence property if the following holds at all $\mathrm{U} \in \mathcal{D}$ : there does not exist a probability distribution $\mathrm{p}^{\mathrm{U}}$ on $\mathrm{F}(\mathrm{U})$ (i.e. a function $\mathrm{p}^{\mathrm{U}}: \mathrm{F}(\mathrm{U}) \rightarrow \mathbb{R}_{+}$such that $\sum_{\mathrm{x} \in \mathrm{F}(\mathrm{U})} \mathrm{p}^{\mathrm{U}}(\mathrm{x})=1$ ) and a probability distribution $\mathrm{q}^{\mathrm{U}}$ on $\mathrm{X}$ (i.e. a function $\mathrm{q}^{\mathrm{U}}: \mathrm{F}(\mathrm{U}) \rightarrow \mathbb{R}_{+}$such that $\sum_{\mathrm{x} \in \mathrm{X}} \mathrm{q}^{\mathrm{U}}(\mathrm{x})=$ 1) such that for all $i \in N, \sum_{x \in F(U)} p^{U}(x) u_{i}(x)<\sum_{x \in X} q^{U}(x) u_{i}(x)$.

An SCFL F on an admissible set $\mathcal{D}$ is said to satisfy the strong non-existence property if the following holds at all $U \in \mathcal{D}$ :

(i) F satisfies the non-existence property.

(ii) for all $y \in X \backslash F(U)$, there exists a probability distribution $\mathrm{p}^{\mathrm{U}}$ on $\mathrm{F}(\mathrm{U}) \cup\{\mathrm{y}\}$ and $\mathrm{q}^{\mathrm{U}}$ on $\mathrm{X}$ such that for all $i \in N, \sum_{x \in F(U) \times\{y\}} p^{U}(x) u_{i}(x)<\sum_{x \in X} q^{U}(x) u_{i}(x)$.

Proposition 3: A social choice functional $\mathrm{F}$ on an admissible set $\mathcal{D}$ satisfies the non-existence property if and only if F satisfies HWU.

Proof: Suppose $F$ on $\mathcal{D}$ satisfies the non-existence property. Let $U \in \mathcal{D}$. Towards a contradiction suppose that there does not exist a probability distribution $\lambda^{\mathrm{U}}$ on $\mathrm{N}$ such that $\mathrm{F}(\mathrm{U})$ is a subset of $\operatorname{Argmax}_{\mathrm{x} \in \mathrm{x}} \sum_{\mathrm{i}=1}^{\mathrm{n}} \lambda_{\mathrm{i}}^{\mathrm{U}} \mathrm{u}_{\mathrm{i}}(\mathrm{x})$. Then the following system of linear equations does not have a non-negative solutions $\alpha=\left(\alpha_{1}, \ldots, \alpha_{n}\right)$ and $<\alpha(x, y) \mid x \in F(U), y \in X>$.

For all $\mathrm{x} \in \mathrm{F}(\mathrm{U})$ and $\mathrm{y} \in \mathrm{X}$ :

$\sum_{\mathrm{i}=1}^{\mathrm{n}} \lambda_{\mathrm{i}}\left(\mathrm{u}_{\mathrm{i}}(\mathrm{x})-\mathrm{u}_{\mathrm{i}}(\mathrm{y})\right)-\alpha(\mathrm{x}, \mathrm{y})=0$, $\sum_{\mathrm{i}=1}^{\mathrm{n}} \lambda_{\mathrm{i}}=1$.

Then by Farkas' Lemma, (see Lahiri (2017)) there exists a function $\mu: F(U) \times X \rightarrow \mathbb{R}$ and a real number $\delta$ such that:

(i) For all $i \in N, \sum_{(x, y) \in F(U) \times x} \mu(x, y)\left[u_{i}(x)-u_{i}(y)\right]+\delta \leq 0$.

(ii) $-\mu(\mathrm{x}, \mathrm{y}) \leq 0$ for all $(\mathrm{x}, \mathrm{y}) \in \mathrm{F}(\mathrm{U}) \times \mathrm{X}$.

(iii) $\delta>0$.

Thus, $\mu(\mathrm{x}, \mathrm{y}) \geq 0$ for all $(\mathrm{x}, \mathrm{y}) \in \mathrm{F}(\mathrm{U}) \times \mathrm{X}$ and $\sum_{(\mathrm{x}, \mathrm{y}) \in \mathrm{F}(\mathrm{U}) \mathrm{X}} \mu(\mathrm{x}, \mathrm{y})\left[\mathrm{u}_{\mathrm{i}}(\mathrm{x})-\mathrm{u}_{\mathrm{i}}(\mathrm{y})\right] \leq-\delta<0$.

Hence $\mu(\mathrm{x}, \mathrm{y}) \geq 0$ for all $(\mathrm{x}, \mathrm{y}) \in \mathrm{F}(\mathrm{U}) \times \mathrm{X}$ and $\mu(\mathrm{x}, \mathrm{y})>0$ for some $(\mathrm{x}, \mathrm{y}) \in \mathrm{F}(\mathrm{U}) \times \mathrm{X}$. Let $\sum_{(\mathrm{x}, \mathrm{y}) \in \mathrm{F}(\mathrm{U}) \times \mathrm{X}} \mu(\mathrm{x}, \mathrm{y})=\mu>$ 0 .

Thus for $i \in N$ it is the case that, $0>\sum_{(\mathrm{x}, \mathrm{y}) \in \mathrm{F}(\mathrm{U}) \times \mathrm{x}} \mu(\mathrm{x}, \mathrm{y})\left[\mathrm{u}_{\mathrm{i}}(\mathrm{x})-\mathrm{u}_{\mathrm{i}}(\mathrm{y})\right]=\sum_{\mathrm{x} \in \mathrm{F}(\mathrm{U})} \mathrm{u}_{\mathrm{i}}(\mathrm{x})\left(\sum_{\mathrm{y} \in \mathrm{x}} \mu(\mathrm{x}, \mathrm{y})\right)-$ $\sum_{\mathrm{y} \in \mathrm{X}} \mathrm{u}_{\mathrm{i}}(\mathrm{y})\left(\sum_{\mathrm{x} \in \mathrm{F}(\mathrm{U})} \mu(\mathrm{x}, \mathrm{y})\right)$.

Let $\mathrm{p}^{\mathrm{U}}: \mathrm{F}(\mathrm{U}) \rightarrow \mathbb{R}_{+}$be such that $\mathrm{p}^{\mathrm{U}}(\mathrm{x})=\frac{\sum_{\mathrm{y} \in \mathrm{X}} \mu(\mathrm{x}, \mathrm{y})}{\mu}$ for all $\mathrm{x} \in \mathrm{F}(\mathrm{U})$ and let $\mathrm{q}^{\mathrm{U}}: \mathrm{F}(\mathrm{U}) \rightarrow \mathbb{R}_{+}$be such that $\mathrm{q}^{\mathrm{U}}(\mathrm{y})=$ $\frac{\sum_{x \in F(U)} \mu(x, y)}{\mu}$. Thus, $\sum_{x \in F(U)} p^{U}(x)=1=\sum_{x \in X} q^{U}(x)$ and for all $i \in N, \sum_{x \in F(U)} p^{U}(x) u_{i}(x)<\sum_{x \in X} q^{U}(x) u_{i}(x)$, contradicting the non-existence property.

Thus, for all $\mathrm{U}=\left(\mathrm{u}_{1}, \ldots, \mathrm{u}_{\mathrm{n}}\right) \in \mathcal{D}$, there exists $\lambda^{\mathrm{U}} \in \Delta^{\mathrm{n}-1}$ such that $\mathrm{F}(\mathrm{U}) \subset \operatorname{Argmax}_{\mathrm{x} \in \mathrm{X}} \sum_{\mathrm{i}=1}^{\mathrm{n}} \quad \mathrm{u}_{\mathrm{i}} \mathrm{u}_{\mathrm{i}}(\mathrm{x})$ and hence $\mathrm{F}$ satisfies HWU.

Now suppose $\mathrm{F}$ on $\mathcal{D}$ satisfies HWU. Then, for all $\mathrm{U}=\left(\mathrm{u}_{1}, \ldots, \mathrm{u}_{\mathrm{n}}\right) \in \mathcal{D}$, there exists $\lambda^{\mathrm{U}} \in \Delta^{\mathrm{n}-1}$ such that $\mathrm{F}(\mathrm{U}) \subset$ $\operatorname{Argmax}_{\mathrm{x} \in \mathrm{X}} \sum_{\mathrm{i}=1}^{\mathrm{n}} \lambda_{\mathrm{i}}^{\mathrm{U}} \mathrm{u}_{\mathrm{i}}(\mathrm{x})$.

Thus, for all $U=\left(u_{1}, \ldots, u_{n}\right) \in \mathcal{D}$, there exists $\lambda^{U} \in \Delta^{n-1}$, such that for all $x \in F(U)$ and $y \in X$ it is the case that $\sum_{\mathrm{i}=1}^{\mathrm{n}} \lambda_{\mathrm{i}}^{\mathrm{U}}\left[\mathrm{u}_{\mathrm{i}}(\mathrm{x})-\mathrm{u}_{\mathrm{i}}(\mathrm{y})\right] \geq 0$.

Thus, for all $U=\left(u_{1}, \ldots, u_{n}\right) \in \mathcal{D}$, there exists $\lambda^{U} \in \Delta^{n-1}$ and a function $\alpha: F(U) \times X \rightarrow \mathbb{R}_{+}$such that for all $\mathrm{x} \in \mathrm{F}(\mathrm{U})$ and $\mathrm{y} \in \mathrm{X}$ it is the case that $\sum_{\mathrm{i}=1}^{\mathrm{n}} \lambda_{\mathrm{i}}^{\mathrm{U}}\left[\mathrm{u}_{\mathrm{i}}(\mathrm{x})-\mathrm{u}_{\mathrm{i}}(\mathrm{y})\right]-\alpha(\mathrm{x}, \mathrm{y})=0$.

Towards a contradiction suppose $\mathrm{F}$ does not satisfy the non-existence property. Then there exists $\mathrm{U}=$ $\left(\mathrm{u}_{1}, \ldots, \mathrm{u}_{\mathrm{n}}\right) \in \mathcal{D}$, a probability distribution $\mathrm{p}^{\mathrm{U}}$ on $\mathrm{F}(\mathrm{U})$ and a probability distribution $\mathrm{q}^{\mathrm{U}}$ on $\mathrm{X}$ such that for all $\mathrm{i} \in \mathrm{N}, \sum_{\mathrm{x} \in \mathrm{F}(\mathrm{U})} \mathrm{p}^{\mathrm{U}}(\mathrm{x}) \mathrm{u}_{\mathrm{i}}(\mathrm{x})<\sum_{\mathrm{x} \in \mathrm{X}} \mathrm{q}^{\mathrm{U}}(\mathrm{x}) \mathrm{u}_{\mathrm{i}}(\mathrm{x})$.

For all $(x, y) \in F(U) \times X$, let $\mu(x, y)=p^{U}(x) q^{U}(y)$. Thus, $\mu(x, y) \geq 0$ for all $(x, y) \in F(U) \times X$.

Since $\sum_{x \in F(U)} p^{U}(x) u_{i}(x)<\sum_{x \in X} q^{U}(x) u_{i}(x)$ for all $i \in N$, there exists $\delta>0$ such that $\sum_{x \in F(U)} p^{U}(x) u_{i}(x)+\delta$ $<\sum_{\mathrm{x} \in \mathrm{X}} \mathrm{q}^{\mathrm{U}}(\mathrm{x}) \mathrm{u}_{\mathrm{i}}(\mathrm{x})$ for all $\mathrm{i} \in \mathrm{N}$.

Note that for all $i \in N, \sum_{x \in F(U)} p^{U}(x) u_{i}(x)=\sum_{(x, y) \in F(U) \times x} \mu(x, y) u_{i}(x)$ and $\sum_{y} x q^{U}(y) u_{i}(y)=$ $\sum_{(\mathrm{x}, \mathrm{y}) \in \mathrm{F}(\mathrm{U}) \times \mathrm{x}} \mu(\mathrm{x}, \mathrm{y}) \mathrm{u}_{\mathrm{i}}(\mathrm{y})$

Thus, 
(i) For all $i \in N, \sum_{(x, y) \in F(U) \times x} \quad(x, y)\left[u_{i}(x)-u_{i}(y)\right]+\delta \leq 0$.

(ii) $-\mu(\mathrm{x}, \mathrm{y}) \leq 0$ for all $(\mathrm{x}, \mathrm{y}) \in \mathrm{F}(\mathrm{U}) \times \mathrm{X}$.

(iii) $\delta>0$.

This contradicts Farkas' lemma. Hence F satisfies the non-existence property. Q.E.D.

Proposition 4: Suppose that a social choice functional $\mathrm{F}$ on an admissible set $\mathcal{D}$ satisfies the strong nonexistence property. Then, F satisfies E-HWU.

Proof: Suppose $\mathrm{F}$ on $\mathcal{D}$ satisfies the strong non-existence property. By proposition 3 , for all $U=$ $\left(\mathrm{u}_{1}, \ldots, \mathrm{u}_{\mathrm{n}}\right) \in \mathcal{D}$, there exists $\lambda^{\mathrm{U}} \in \Delta^{\mathrm{n}-1}$ such that $\mathrm{F}(\mathrm{U}) \subset \operatorname{Argmax}_{\mathrm{x}}{ }_{\mathrm{x}} \sum_{\mathrm{i}=1}^{\mathrm{n}} \lambda_{\mathrm{i}}^{\mathrm{U}} \mathrm{u}_{\mathrm{i}}(\mathrm{x})$. Let $\mathrm{y} \in \mathrm{X} \backslash \mathrm{F}(\mathrm{U})$. By strong nonexistence property, there exists a probability distribution $\mathrm{p}^{\mathrm{U}}$ on $\mathrm{F}(\mathrm{U}) \cup\{\mathrm{y}\}$ and $\mathrm{q}^{\mathrm{U}}$ on $\mathrm{X}$ such that for all $\mathrm{i} \in \mathrm{N}$, $\sum_{\mathrm{x} \in \mathrm{F}(\mathrm{U}) \times \mathrm{y}\}} \mathrm{p}^{\mathrm{U}}(\mathrm{x}) \mathrm{u}_{\mathrm{i}}(\mathrm{x})<\sum_{\mathrm{x} \in \mathrm{X}} \mathrm{q}^{\mathrm{U}}(\mathrm{x}) \mathrm{u}_{\mathrm{i}}(\mathrm{x})$. Towards a contradiction suppose $\mathrm{y} \in \operatorname{Argmax}_{\mathrm{x} \in \mathrm{X}} \sum_{\mathrm{i}=1}^{\mathrm{n}} \lambda_{\mathrm{i}}^{\mathrm{U}} \mathrm{u}_{\mathrm{i}}(\mathrm{x})$.

Then the system

$\sum_{\mathrm{i}=1}^{\mathrm{n}} \mu_{\mathrm{i}}\left(\mathrm{u}_{\mathrm{i}}(\mathrm{z})-\mathrm{u}_{\mathrm{i}}(\mathrm{x})\right)-\alpha(\mathrm{z}, \mathrm{x})=0$ for all $\mathrm{z} \in \mathrm{F}(\mathrm{U}) \cup\{\mathrm{y}\}, \mathrm{x} \in \mathrm{X}$,

$\sum_{\mathrm{i}=1}^{\mathrm{n}} \alpha_{\mathrm{i}}=1$,

has a non-negative solution.

Since for all $i \in N, \sum_{x \in F(U) \times\{y\}} p^{U}(x) u_{i}(x)<\sum_{x \in X} q^{U}(x) u_{i}(x)$, there exists $\delta>0$, such that for all $i \in N$, $\sum_{\mathrm{x} \in \mathrm{F}(\mathrm{U}) \times\{\mathrm{y}\}} \mathrm{p}^{\mathrm{U}}(\mathrm{x}) \mathrm{u}_{\mathrm{i}}(\mathrm{x})-\sum_{\mathrm{x} \in \mathrm{X}} \mathrm{q}^{\mathrm{U}}(\mathrm{x}) \mathrm{u}_{\mathrm{i}}(\mathrm{x})+\delta<0$.

Let $\mu:(\mathrm{F}(\mathrm{U}) \cup\{\mathrm{y}\}) \times \mathrm{X} \rightarrow \mathbb{R}_{+}$be defined as $\mu(\mathrm{z}, \mathrm{x})=\mathrm{p}^{\mathrm{U}}(\mathrm{z}) \mathrm{q}^{\mathrm{U}}(\mathrm{x})$ for all $(\mathrm{z}, \mathrm{x}) \in(\mathrm{F}(\mathrm{U}) \cup\{\mathrm{y}\}) \times \mathrm{X}$.

Thus, $\sum_{\mathrm{z} \in \mathrm{F}(\mathrm{U}) \times\{\mathrm{y}\}} \mathrm{p}^{\mathrm{U}}(\mathrm{z}) \mathrm{u}_{\mathrm{i}}(\mathrm{z})=\sum_{(\mathrm{z}, \mathrm{x}) \in(\mathrm{F}(\mathrm{U}) \times\{\mathrm{y}\}) \times \mathrm{x}} \mu(\mathrm{z}, \mathrm{x}) \mathrm{u}_{\mathrm{i}}(\mathrm{z})$ and $\sum_{\mathrm{x}} \mathrm{x} \mathrm{q}^{\mathrm{U}}(\mathrm{x}) \mathrm{u}_{\mathrm{i}}(\mathrm{x})=$ $\sum_{(\mathrm{z}, \mathrm{x}) \in(\mathrm{F}(\mathrm{U}) \times\{\mathrm{y}\}) \times \mathrm{x}} \mu(\mathrm{z}, \mathrm{x}) \mathrm{u}_{\mathrm{i}}(\mathrm{x})$.

Thus,

(i) For all $\mathrm{i} \in \mathrm{N}, \sum_{(\mathrm{z}, \mathrm{x}) \in(\mathrm{F}(\mathrm{U}) \times\{\mathrm{y}\}) \times \mathrm{x}} \mu(\mathrm{z}, \mathrm{x})\left[\mathrm{u}_{\mathrm{i}}(\mathrm{z})-\mathrm{u}_{\mathrm{i}}(\mathrm{x})\right]+\delta \leq 0$.

(ii) $-\mu(z, x) \leq 0$ for all $(z, x) \in(F(U) \cup\{y\}) \times X$.

(iii) $\delta>0$.

This contradicts Farkas' lemma.

Thus, $y \notin \operatorname{Argmax}_{\mathrm{x} \in \mathrm{X}} \sum_{\mathrm{i}=1}^{\mathrm{n}} \lambda_{\mathrm{i}}^{\mathrm{U}} \mathrm{u}_{\mathrm{i}}(\mathrm{x})$ and so $\mathrm{F}(\mathrm{U})=\operatorname{Argmax}_{\mathrm{x} \in \mathrm{X}} \sum_{\mathrm{i}=1}^{\mathrm{n}} \lambda_{\mathrm{i}}^{\mathrm{U}} \mathrm{u}_{\mathrm{i}}(\mathrm{x})$.

Hence F satisfies E-HWU. Q.E.D.

\section{ALTERNATIVE INTERPRETATION FROM THE PERSPECTIVE OF A FIXED AGENDA CHOICE FUNCTIONAL}

There are interesting possibilities if we interpret $\mathrm{N}=\{1, \ldots, \mathrm{n}\}$ to be a collection of ' $\mathrm{n}$ ' different states on nature, in which case it is more appropriate to refer to an SCFL as a (fixed agenda) choice functional (CFL). The implicit reference to fixed agenda, reiterates that the set of alternatives from which choices are made, is fixed.

A CFL F on an admissible set $\mathcal{D}$ is said to be:

(i) The mini-max (pessimistic) rule if for all $U=\left(\mathrm{u}_{1}, \ldots, \mathrm{u}_{\mathrm{n}}\right) \in \mathcal{D}: F(\mathrm{U})=$ $\operatorname{Arg} \max _{\mathrm{x} \in \mathrm{X}}\left(\min _{\mathrm{i} \in \mathrm{N}} \mathrm{u}_{\mathrm{i}}(\mathrm{x})\right)$;

(ii) The maxi-max (optimistic) rule if for all $\mathrm{U}=\left(\mathrm{u}_{1}, \ldots, \mathrm{u}_{\mathrm{n}}\right) \in \mathcal{D}: \mathrm{F}(\mathrm{U})=$ $\operatorname{Arg} \max _{\mathrm{x} \in \mathrm{X}}\left(\max _{\mathrm{i} \in \mathrm{N}} \mathrm{u}_{\mathrm{i}}(\mathrm{x})\right)$;

(iii) The Hurwicz- $\alpha$ pessimism-optimism rule where $\alpha$ is a real number lying in the closed interval $[0,1]$ such that for all $\mathrm{U}=\left(\mathrm{u}_{1}, \ldots, \mathrm{u}_{\mathrm{n}}\right) \in \mathcal{D}: \mathrm{F}(\mathrm{U})$ $=\operatorname{Arg} \max _{\mathrm{x} \in \mathrm{X}}\left(\alpha \min _{\mathrm{i} \in \mathrm{N}} \mathrm{u}_{\mathrm{i}}(\mathrm{x})+(1-\alpha) \max _{\mathrm{i} \in \mathrm{N}} \mathrm{u}_{\mathrm{i}}(\mathrm{x})\right)$.

The utilitarian social choice functional is the well-known solution rule associated with the Laplace criterion and may be called the Laplace choice functional or the uniform choice functional. Harsanyi's Weighted Utilitarianism that we discussed in section 4, may be viewed as expected utility maximization with the probabilities of the states of nature depending on the evaluation profile.

Motivation for the choice rules mentioned above can be found in chapter 12 of Taylor (2017).

All these rules apply to choose situations under complete uncertainty. Their axiomatic characterization could be a possible subject for future research. 


\section{CONCLUSION}

In this section let us recall the main contributions of this paper.

In this paper, we formally introduce the concept of a social choice functional, which is a rule which assigns to

each evaluation profile, a non-empty subset of alternatives. The first major takes away from our discussion

reported in this paper, are new axiomatic characterizations of the utilitarian and weighted utilitarian social

choice functional. We define the utilitarian social choice functional and provide two axiomatic

characterizations for it. The utilitarian social choice functional chooses at each evaluation profile, exactly those alternatives which maximize the sum of the evaluations. Given the exact similarity between the utilitarian social choice functional and the Laplace choice functional, the importance of these two axiomatic characterizations cannot be overemphasized. Subsequently we consider Harsanyi's weighted utilitarianism which is a property that selects alternatives from those which maximize a weighted sum of the individual evaluations. As in Harsanyi's pioneering work on the subject (Harsanyi (1955)), the weights attached to the individual evaluations, may depend on the evaluation profile under consideration. This is precisely where our similarity with the Harsanyi (1955) model ends. Our first result in this context provides a necessary and sufficient condition for a social choice functional to satisfy Harsanyi’s weighted utilitarianism. A slightly stronger criterion than Harsanyi's weighted utilitarianism is that at each evaluation profile the chosen set should coincide with (and not merely be a subset of) the set of weighted utility maximizers for some nonnegative weights which add to one. We call this criterion exact Harsanyi's weighted utilitarianism. Our second result in this context provides a sufficient condition for a social choice functional to satisfy Harsanyi's weighted utilitarianism. In addition to the results themselves, the methodology that we use to prove them are new (and hence original) for the framework and solution concepts we are concerned with here and related solution concepts as well.

A second major take-away from our discussion is that the Arrow-Sen framework of social choice, and many of its subsequent generalizations, particularly its generalizations due to Gibbard (1973), Satterthwaite (1975) and Denicolo (1985) are amenable to several different kinds of interpretations. Its relevance is not restricted to group decision making alone, where it is undeniably extremely relevant. It is also relevant for the analysis of individual decision making- whether it is multi-criteria decision making or decision making under uncertainty. After all, decision theory is not a compilation of insipid and irrelevant formulas and equations; apart from the aesthetic beauty of its internal logic it relates significantly to the real world through the aspects of practical decision making that it addresses.

Acknowledgment: This paper has benefitted immensely from comments and suggestions by Professor Prasanta Pattanaik to whom I remain very grateful. I would like to put on record my gratitude to Pratik Lahiri and Urmee Khan for valuable contributions while putting together references and Soumyen Sikdar for provocative/encouraging comments that made sure that I remain on guard while reporting the results. I would also like to thank Peter Wakker for comments and him and Smruti Ranjan Behra for additional references related to the paper. I would like to express my gratitude to two anonymous referees of this journal for very kindly reading my paper and suggesting several desirable revisions, which I feel, has lead to the overall improvement of the paper. Last but not the least, I would like to put on record my sincere gratitude to my friend and respected senior colleague Professor Carlos Bouza for suggestions and help in revising this paper.

(Yeh dosti hum nahi todenge-Anand Bakshi). In any case, no one other than the author is responsible for the shortcomings of the paper.

RECEIVED: OCTOBER, 2018. REVISED: MARCH, 2019.

\section{REFERENCES}

[1] ALEMANTE, F., CAMPBELL, D. and KELLY, J.S. (2016): Characterizing the resolute part of monotonic social choice correspondences. Economic Theory, 62, 765-783.

[2] D'ASPREMONT, C. and GEVERS, L. (2002): Social welfare functional and interpersonal comparability. In K. Arrow, A. Sen and K. Suzumura (eds.), Handbook of Social Choice and Welfare, Volume 1, 459-541. Elsevier Science, Amsterdam.

[3] DENICOLO, V. (1985): Independent social choice correspondences are dictatorial. Economics Letters, $19,9-12$.

[4] DENICOLO, V. (1993): Fixed Agenda Social Choice Theory: Correspondence and Impossibility 
| Theorems for Social Choice Correspondences and Social Decision Functions. Journal of Economic Theory 59, 324-332.

[5] DHILLON, A. (1998): Extended Pareto rules and relative utilitarianism. Social Choice and Welfare, 15, $521-542$.

[6] DHILLON, A. and MERTENS, J.-F. (1999): Relative utilitarianism. Econometrica ,67, 417-498.

[7] GIBBARD, A. (1973): Manipulation of voting schemes. Econometrica, 41, 587-601.

[8] HARSANYI, J.C. (1955): Cardinal Utility, Individualistic Ethics, and Interpersonal Comparisons of

Utility. Journal of Political Economy, 63, 309-321.

[9] HILLINGER, C. (2005) : The Case for Utilitarian Voting. Munich Discussion Paper, No. 2005-11, Ludwig-Maximilians-Universität München, Volkswirtschaftliche Fakultät, München, http://nbn-

resolving.de/urn:nbn:de:bvb:19-epub-653-8. (This Version is available at:

http://hdl.handle.net/10419/104157).

[10] KELLY, J.S. (2018): Characterization of the Pareto social choice correspondence. Unpublished and dated March 10, 2018.( https://arxiv.org/abs/1804.04047).

[11] KELLY, J.S. and QI, S. (2018): Balancedness of social choice correspondences. Unpublished and dated Mach 9, 2018.( https://arxiv.org/abs/1804.02990).

[12] LAHIRI, S. (2017): A Short Note On Strong Duality: Without Simplex and Without Theorems of

| Alternatives. Mathematical Economics, 13, 59-66.

[13] LAHIRI, S. (2018): On a theorem due to Alan D. Taylor about aggregation of preferences. (forthcoming) Arthaniti: Journal of Economic Theory and Practice.

| [14] ROSS, S.M. (2000): Topics in Finite and Discrete Mathematics. Cambridge University Press, Cambridge.

[15] RUBInsteIn, A. (2012): Lecture Notes in Microeconomic Theory: The Economic Agent. Princeton University Press, Princeton and Oxford.

[16] SATTERTHWAITE, M. (1975): Strategy-proofness and Arrow's conditions: Existence and correspondence theorems for voting procedures and social welfare functions. Journal of Economic Theory, $10,87-217$.

[17] SCOTT, D. (1964): Measurement Structures and Linear Inequalities. Journal of Mathematical Psychology, 1, 233-247.

[18] SEN, A. K. (1970): Collective Choice and Social Welfare. Holden Day, San Francisco. [19] SHAPIRO, L. (1977): Necessary and Sufficient Conditions for Expected Utility Maximization: The Finite Case with a Partial Order. Discussion paper number 77-80, Center for Economic Research, Department of Economics, University of Minnesota.

[20] TAYLOR, B.W. (2017): Introduction to Management Science, $\left(12^{\text {th }}\right.$ edition), Pearson India Education Services Pvt. Ltd., Calcutta. 